\title{
Engineering and Manufacturing Technology of Green Epoxy Resin Coatings Modified with Recycled Fine Aggregates
}

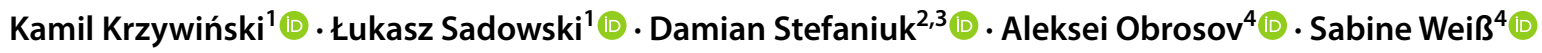

Received: 8 December 2020 / Revised: 10 June 2021 / Accepted: 4 July 2021 / Published online: 12 July 2021

(c) The Author(s) 2021

\begin{abstract}
Nowadays, the recycled fine aggregate sourced from construction and demolition waste is not frequently used in manufacturing of epoxy resin coatings. Therefore, the main novelty of the article is to prepare green epoxy resin coatings modified with recycled fine aggregate in a replacement ratio of natural fine aggregate ranged from 20 to $100 \%$. The microstructural properties of the aggregates and epoxy resin were analyzed using micro-computed tomography, scanning electron microscopy and nanoindentation. The macroscopic mechanical properties were examined using pull-off strength tests. The highest improvement of the mechanical properties was observed for epoxy resin coatings modified with $20 \%$ of natural fine aggregate and $80 \%$ of recycled fine aggregate. It has been found that even $100 \%$ of natural fine aggregate can be successfully replaced using the recycled fine aggregate with consequent improvement of the pull-off strength of analyzed epoxy resin coatings. In order to confirm the assumptions resulting from the conducted research, an original analytical and numerical failure model proved the superior behavior of modified coating was developed.
\end{abstract}

Keywords Manufacturing $\cdot$ Wear $\cdot$ Composite $\cdot$ Epoxy resin coating $\cdot$ Recycled aggregate $\cdot$ Green material

Kamil Krzywiński

kamil.krzywinski@pwr.edu.pl

Łukasz Sadowski

lukasz.sadowski@pwr.edu.pl

Damian Stefaniuk

damian.stefaniuk@pwr.edu.pl

Aleksei Obrosov

aleksei.obrosov@b-tu.de

Sabine Weiß

sabine.weiss@b-tu.de

1 Department of Building Engineering, Wroclaw University of Science and Technology, Wybrzeże Wyspiańskiego 27, 50-370 Wroclaw, Poland

2 Department of Geotechnics, Hydrotechnics, Underground and Water Construction, Wrocław University of Science and Technology, Wybrzeże Wyspiańskiego 27,

50-370 Wroclaw, Poland

3 Department of Civil and Environmental Engineering, Cullen College of Engineering, University of Houston, Texas 77204, USA

4 Department of Physical Metallurgy and Materials Technology, Brandenburg University of Technology, 03046 Cottbus, Germany

\section{Introduction}

Worldwide manufacturing development [1] in the twentieth and twenty-first century is based on the fast-growing construction industry [2, 3]. However, due to this development, the construction industry is responsible for generating the highest amount of waste in the EU (924 million tons in 2016 [4]; Fig. 1a). Most constructions are designed as reinforced concrete buildings, and the concrete mixture in $75 \%$ of such objects is based on aggregate [5]. Thus, the extraction of aggregates is around two billion tons per year (Fig. 1b), with a growing tendency within the past few years [6]. The extraction of river sand has a negative impact on the environment due to it not being easily renewable in the ecosystem. This process of environmental degradation should therefore be avoided, or at least decreased.

Prosperous cities collect public funds that can be spent on the renovation of historical structures [7-9]. However, the renovation is not taken into account if there are no historical reasons to save the building, or if it does not meet the standard safety requirements. In such cases, old structures are prepared for demolition $[10,11]$. After the demolition of an old building, millions of tons of waste concrete are stored [12], which can be used to obtain recycled aggregate [13]. 
(a)

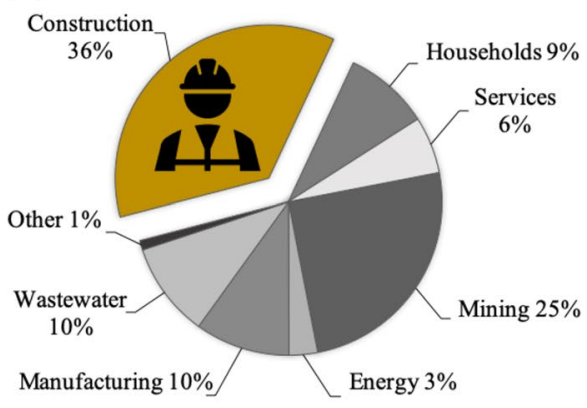

(b)

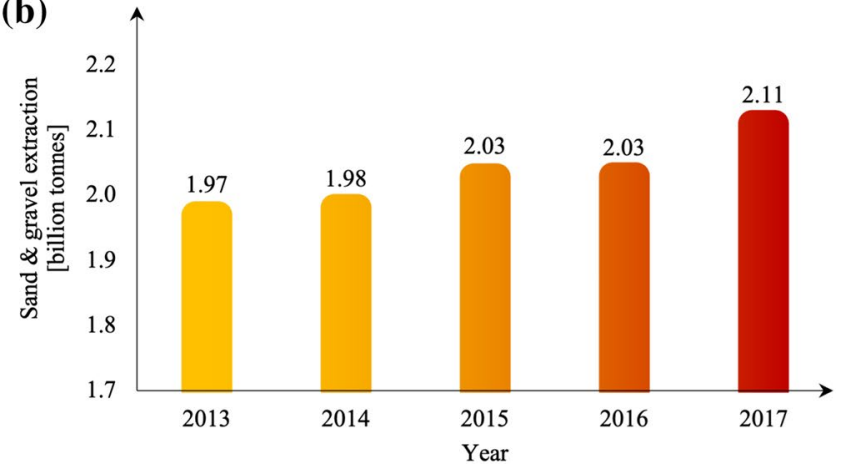

Fig. 1 Statistics for twenty-eight European countries: a waste generation in 2016 by economic activities and households (based on the data presented in [5]); b sand and gravel extraction in recent years (based on the data presented in [6])

Recycled coarse aggregate is commonly used as a replacement for standard aggregate in concrete mixtures [14-16], and is also widely used to strengthen road substrates [17, 18]. In literature, there are well-known approaches of using marble [19-21], granite [22-24], ceramic [25, 26], electric arc furnace slag [27], and steel slag [28, 29] as recycled coarse aggregate. Gao et al. [30] performed tests on recycled aggregate concrete strengthened with polyester FRP-PVC (fiber reinforced polymer-polyvinyl chloride) tubes. The application of the PVC tubes did not provide an increase in the compressive strength, but significantly improved ductility.

The utilization of recycled fine aggregate (RFA) is problematic, and its volume continues to grow around the world, in turn destroying the surrounding environment [31, 32]. It should be noted, however, that fine aggregate has the same properties as the old concrete structure that it came from [33-35]. Therefore, actions should be taken in order to find applications for this material.

Moreover, due to the rapid growth of industry, there is a need to build new storage halls, the indoor floors of which can be covered with cement mortar [36-38] or epoxy resin coatings $[39,40]$. Epoxy resins are widely used in the coating industry. Wei et al. [41] stated that this material has become more common because of its excellent performance. It can be applied on the surfaces of metal and non-metal structures for protection and/or decoration purposes. A concrete substrate covered with epoxy coating is well protected due to the coating's high chemical and mechanical resistance [42-45] and high pull-off strength to the concrete substrate [46-48]. Sadowski and Szymanowski $[49,50]$ pointed out that pull-off strength provides high durability of epoxy resinconcrete composite. The epoxy resin can be used in epoxy/ glass fiber composite formulations. Colangelo et al. [51] determined the pull-out strength between an epoxy resin and three different substrates: conventional concrete, artificial aggregate concrete, and geopolymer. The study highlighted their potential use for civil engineering applications. In a previous study [52], the authors of the present paper used texturing as a surface treatment method for concrete substrates to increase the pull-off strength between the epoxy resin and the concrete substrate layer. The results were satisfying, but texturing increased the coarseness of the concrete substrate, which resulted in the higher consumption of epoxy resin. The manufacturers of epoxy resin allow river aggregate $(0-2 \mathrm{~mm})$ to be added as an extender to epoxy resin coatings to increase their volume. However, the extraction of river aggregate mostly takes place far away from where it is used. The source of this material is not renewable and its high extraction around the globe has a negative impact on the environment.

Some researchers have tried to use different types of recycled materials as an additive to epoxy resin. For example, Huan et al. [53] used recycled short carbon fibers in high-performance epoxy composites. The authors achieved significant enhancements of tensile and flexural properties, interlaminar shear strength, storage modulus, and electromagnetic interference shielding. However, this proposal cannot be used for industrial floor coatings because of the too complicated preparation process of this composite (e.g. preparation in a temperature of around $100{ }^{\circ} \mathrm{C}$ for a few hours). This even makes it impossible to prepare this type of coating in large-area halls. The other possibility is to use nanoparticles [54] or powders [55] which significantly enhance mechanical and thermal properties of epoxy resins. However, this solution seems to be too expensive. The answer is to utilize the waste [56-59]. The preliminary studies show that the utilization of RFA in epoxy resin could reduce preparation costs of coating [57]. However, it does not change compressive and flexural tensile strength of epoxy resin-concrete composite. The preliminary studies also show that with high amount of RFA filler the pull-off strength of epoxy resin to concrete substrate may increase significantly [60]. 
When considering the above, the aim of this article was to obtain an epoxy resin with improved parameters with the use of RFA. In order to present the research gaps, a literature survey was performed for the combination of keywords "Coating", "Resin", "Epoxy" and "Recycled aggregate" using the Scopus Elsevier database. The results are summarized in Table 1.

As can be seen in Table 1, the research interest in epoxy resin coatings is large and consists of more than 6000 publications until 2020. However, there is a significant lack of knowledge in the field of epoxy resin coatings with recycled aggregates. Only one article, published in 1989, was found with regards to this research area [61]. This may be due to the fact that current papers describe studies in which recycled aggregate is used in the construction of roads or as a component of concrete. Thus, the novelty of this study is associated with the application of RFA in epoxy resin coatings. The main focus of this research is to analyze the influence of the partial replacement of river sand with RFA on the properties of epoxy resin coatings and concrete components. Moreover, in this article, the failure mechanism of thin epoxy resin coatings with fine aggregate as an extender during the pull-off strength test is explained by analytical and numerical calculations. To the best of the author's knowledge, this type of approach has not yet been investigated for floor layers.

\section{Research significance}

The development of production lines or the chemical industry requires the use of more advanced techniques of protecting floors. Therefore, epoxy resin is becoming more popular in the civil engineering industry and is widely used as a floor coating. The increasing interest in epoxy resin coatings, and the low knowledge concerning their durability, was a reason to conduct the study on epoxy resin coating extended with different fine aggregates. In this paper, the pull-off strength of epoxy resin coating was taken into account as a basic property of industrial floors. There is not a sufficient number of research studies that accurately describe the pull-off strength mechanism of epoxy resin coatings that are applied to concrete substrate, and most of them just present the results. Furthermore, there is a lack of research involving the analysis of the mechanism of the pull-off strength of epoxy resin extended with fine aggregate, especially with RFA. Damage to a composite made of epoxy resin coating and concrete substrate occurs in its weakest layer, which is usually the concrete substrate. However, the stress transmission by epoxy resin coating extended with fine aggregate has a significant influence on the pull-off strength of composites. Therefore, in this paper, the type of extender and its effect on the pull-off strength of epoxy resin coating were deeply analyzed. A detailed analysis of the pull-off strength mechanism was shown using an analytical and numerical approach. The presented results fill the knowledge gap in the literature concerning epoxy resin floor coatings. This study also presents the possibility of utilizing RFA obtained from demolition wastes in thin epoxy resin floor coatings. In addition, the presented approaches that describe the failure mechanism can be easily used when analysing epoxy resin coatings that contain other types of fillers.

\section{Materials and Methods}

\subsection{Substrate}

The substrate was prepared in a wooden formwork with dimensions of $900 \times 300 \times 40 \mathrm{~mm}$. This
Table 1 Number of articles in 2020 related to "epoxy resin coatings with recycled aggregates" searched for in the article title, abstract and keywords in the Scopus Elsevier database (date of search: 29.04.2020)

\begin{tabular}{llr}
\hline No & Keyword & Number of articles \\
\hline 1 keyword & Coating & 396425 \\
1 & Resin & 270257 \\
2 & Epoxy & 106232 \\
3 & Recycled aggregate & 5174 \\
4 & & \\
2 keywords & Coating + resin & 16167 \\
1 & Coating + epoxy & 10095 \\
2 & Coating + recycled aggregate & 78 \\
3 & & 6051 \\
3 keywords & Coating + epoxy + resin & 2 \\
1 & Coating + epoxy + recycled aggregate & 1 \\
2 & & \\
4 keywords & Coating + epoxy + resin + recycled aggregate & \\
1 & & \\
\hline
\end{tabular}


substrate was divided into twelve smaller samples each of $150 \times 150 \times 40 \mathrm{~mm}$. In order to decrease the friction between the form and the sample, internal walls were covered with oil. The substrate was prepared using a ready concrete mixture of class C16/20. This composition consists of limestone powder, Type I Portland cement, quartz aggregate with a grain size of $0-4 \mathrm{~mm}$, and other additives. In this research, the weight ratio of the water-readymix was 0.1 , and the average mixing time was $180 \mathrm{~s}$.

\subsection{Preparation of the Substrate Surface}

As recommended by the manufacturer of the epoxy resin, the concrete substrate surface has to be treated by grinding and by applying a bonding agent [62-64] in order to obtain a pull-off strength higher than $1.5 \mathrm{MPa}$ (normative minimal admissible value of the pull-off strength after 7 days according to [65]). In this research, after 28 days of curing, the concrete substrate surface was grinded without applying the bonding agent. In paper [52], the concrete substrate surfaces were also prepared in such a way. The pull-off strength values for these specimens were around 1.8 MPa. Therefore, the authors decided not to use the bonding agent, as it could significantly affect the obtained test results. The samples $(150 \times 150 \times 40 \mathrm{~mm})$ were grinded mechanically using a diamond grinding wheel (Fig. 2a). Then, the concrete surface was analysed using machine vision $[66,67]$ in order to detect possible defects occurred after mechanical treatment. Damaged specimens were dismissed.

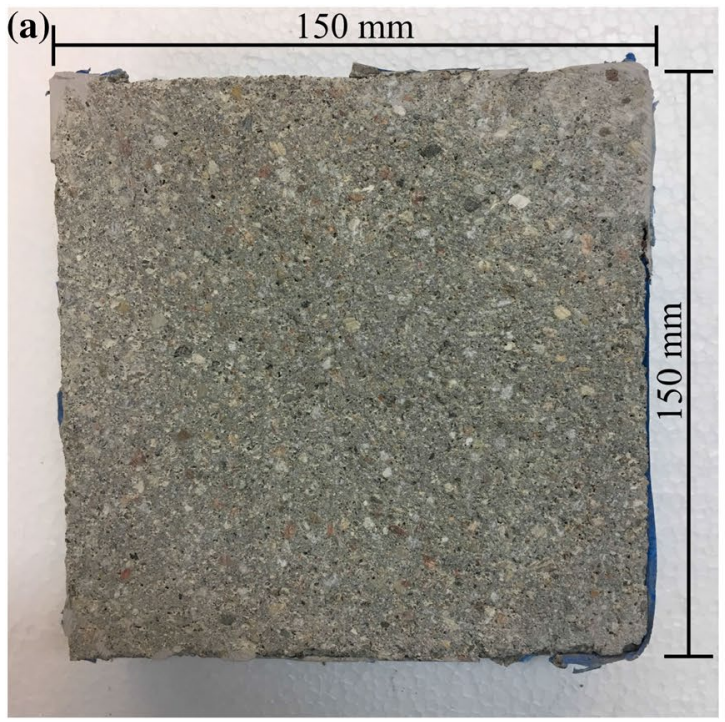

\subsection{Epoxy Resin Coating}

The coating was made of commercially available epoxy resin with a Young modulus of $6.1 \mathrm{GPa}$. It consisted of three components: component A (base) - an epoxy resin based on bisphenol; component $\mathrm{B}$ - $\mathrm{a}$ hardener based on aliphatic polyamines; and component $\mathrm{C}$ - the manufacturer of the epoxy resin allows aggregate to be added to the mixture when the coating thickness is around $1-3 \mathrm{~mm}$, and therefore the third component is a fine aggregate acting as an extender. For $3 \mathrm{~mm}$ coatings, the weight ratio of A:B:C was 100:25:75. The weight ratio of components was based on the suggestion of the best proportion declared by the manufacturer for epoxy resin (A), hardener (B), and sand extender (C) [68]. All the components were mixed together in a container for 3 min using a drill with a paddle to obtain a uniform consistency (Fig. 3). During the mixing, special attention was paid to mixing the epoxy resin that was covering the walls of the container. The speed of mixing was $280 \mathrm{rpm}$, and the maximum speed declared by the manufacturer should not be higher than $300 \mathrm{rpm}$. The concrete sample covered with epoxy resin was cured in a controlled laboratory environment with relative humidity of less than $60 \%$, and at a temperature of $21 \pm 2{ }^{\circ} \mathrm{C}$. In these conditions, the epoxy resin obtains its full load capacity after 3 days of curing; chemical resistance after 7 days of curing; and water resistance after $16 \mathrm{~h}$ of curing [68]. A macroscale test was performed 7 days after applying the epoxy resin.

\subsection{Aggregate}

In this study, due to economic reasons, natural fine aggregate (NFA) was used as a filler in epoxy resin. Not using a

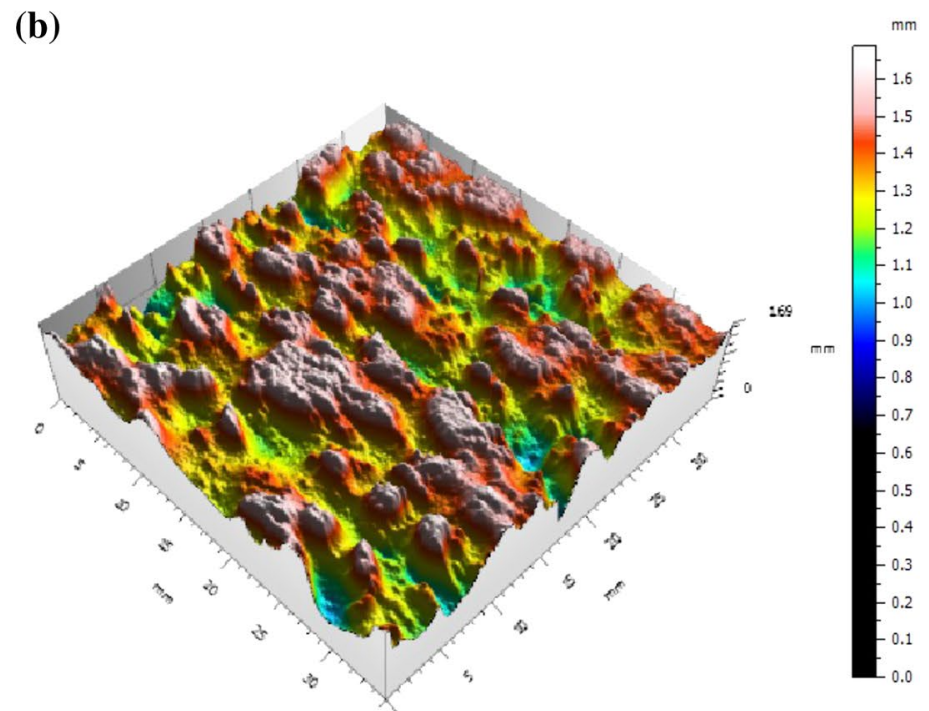

Fig. 2 The surface of the substrate after mechanical grinding: a optical view, b 3D isometric view 
(a)

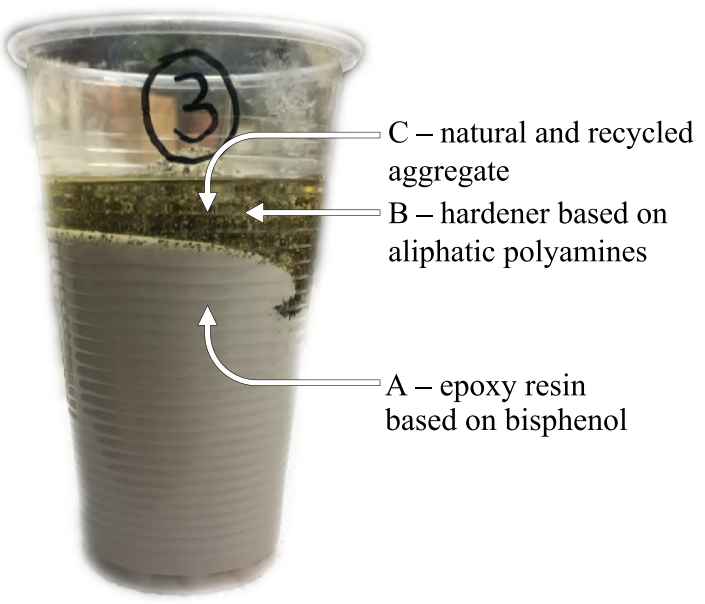

(b)

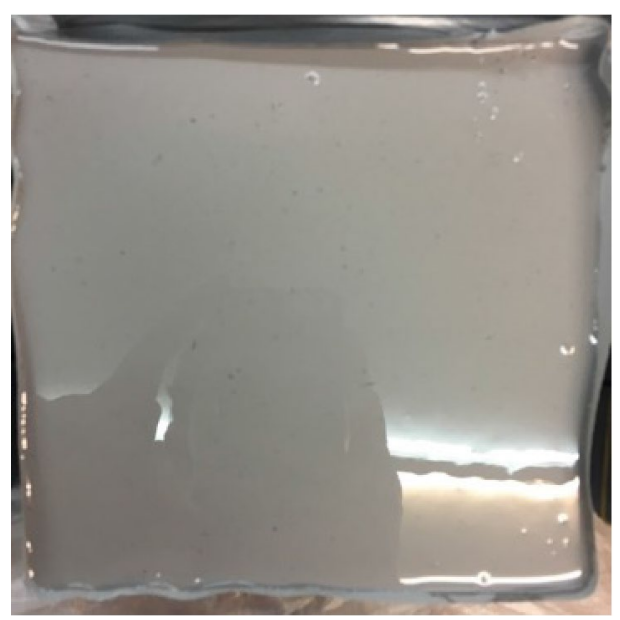

Fig. 3 Epoxy resin coating: a Components-A, B \& C; b sample after pouring fresh epoxy resin

filler in the case of $3 \mathrm{~mm}$ thick coatings leads to enormous costs associated with the purchasing of epoxy resin. However, river aggregate comes from natural sources, and its extraction has a negative impact on the environment. In order to reduce the volume of NFA, the researchers used RFA to partially replace NFA. The RFA was prepared in a way to obtain the same particle size distribution curve as was obtained for the NFA. X\% of the RFA and Y\% of the NFA were mixed for each fraction to prepare the aggregate mixture (Fig. 4a). All the fractions were then mixed together. One sample with $100 \%$ of the NFA content, four samples with different proportions of RFA and NFA, and one sample with the $100 \%$ RFA content were prepared (Fig. 4b). This procedure aimed to select the best proportion of aggregates, with a particular emphasis on improving the pull-off strength between the epoxy resin coating and the concrete substrate. Similar approach of mixing aggregates was performed in $[57,60]$.

River aggregate is the most popular material in the building industry, and is extracted in most countries around the world. It is commonly used for complete concrete mortar mixes. In this study, NFA with a grain size of 0-2 $\mathrm{mm}$ was used as an extender for the epoxy resin coating. Figure $5 \mathrm{~d}$ compares the particle size distribution curve for the RFA and NFA with the minimum and maximum particle size distribution curve for the sand that is commonly used in the concrete mix. The information from the manufacturer of the sand concerning the NFA is presented in Table 2.

In this study, the RFA (Przedsiębiorstwo Rodzinne Merta \& Merta Sp.z o.o., Wroclaw, Poland) was prepared with regards to the particle size distribution curve that was obtained for the NFA (Fig. 5). This procedure enabled the obtained test results to be compared for two different aggregates.

\subsection{Macroscale Laboratory Tests}

The effect of different percentages of the NFA and RFA in the epoxy resin coating was analyzed with regards to its adhesion and cohesion to the surface of the concrete substrate. The adhesion and cohesion were tested using the pulloff strength test. Pull-off strength tests using an automatic adhesion tester (DY-216, Proceq, Switzerland; Fig. 6c) were performed according to ASTM D4541 [69]. Each sample was tested three times in order to obtain the average value of its pull-off strength, as was the case in paper [70]. In order not to disturb the results, the increase in the tensile strength transmitted to the steel disc was very slow and smooth. The load increasing speed was $0.05 \mathrm{MPa} / \mathrm{s}$. According to the ASTM D4541 standard [69], the failure or the maximum stress should occur in $100 \mathrm{~s}$ or less. In this study, all the failures occurred in less than $40 \mathrm{~s}$.

\subsection{Microscale Laboratory Tests}

The best combination of NFA and RFA can be defined with the use of micro tests. For a better understanding, microscale laboratory tests were performed, in which X-ray microcomputed tomography (micro-CT) was used to characterize the morphology of the NFA and RFA. Scanning electron microscopy (SEM) with energy dispersive X-ray spectroscopy (EDS) was used to compare the differences in their elemental composition. Finally, the mechanical properties, such as indentation modulus $(M)$ and hardness $(H)$, were evaluated using the nanoindentation technique and then compared.

Three samples of the aggregate (NFA, RFA and mixed fine aggregate (MFA)) were scanned separately in cylindrical containers (diameter: $2 \mathrm{~cm}$, height: $4 \mathrm{~cm}$ ) without compaction of the aggregate grains. 3D images were obtained 
(a)

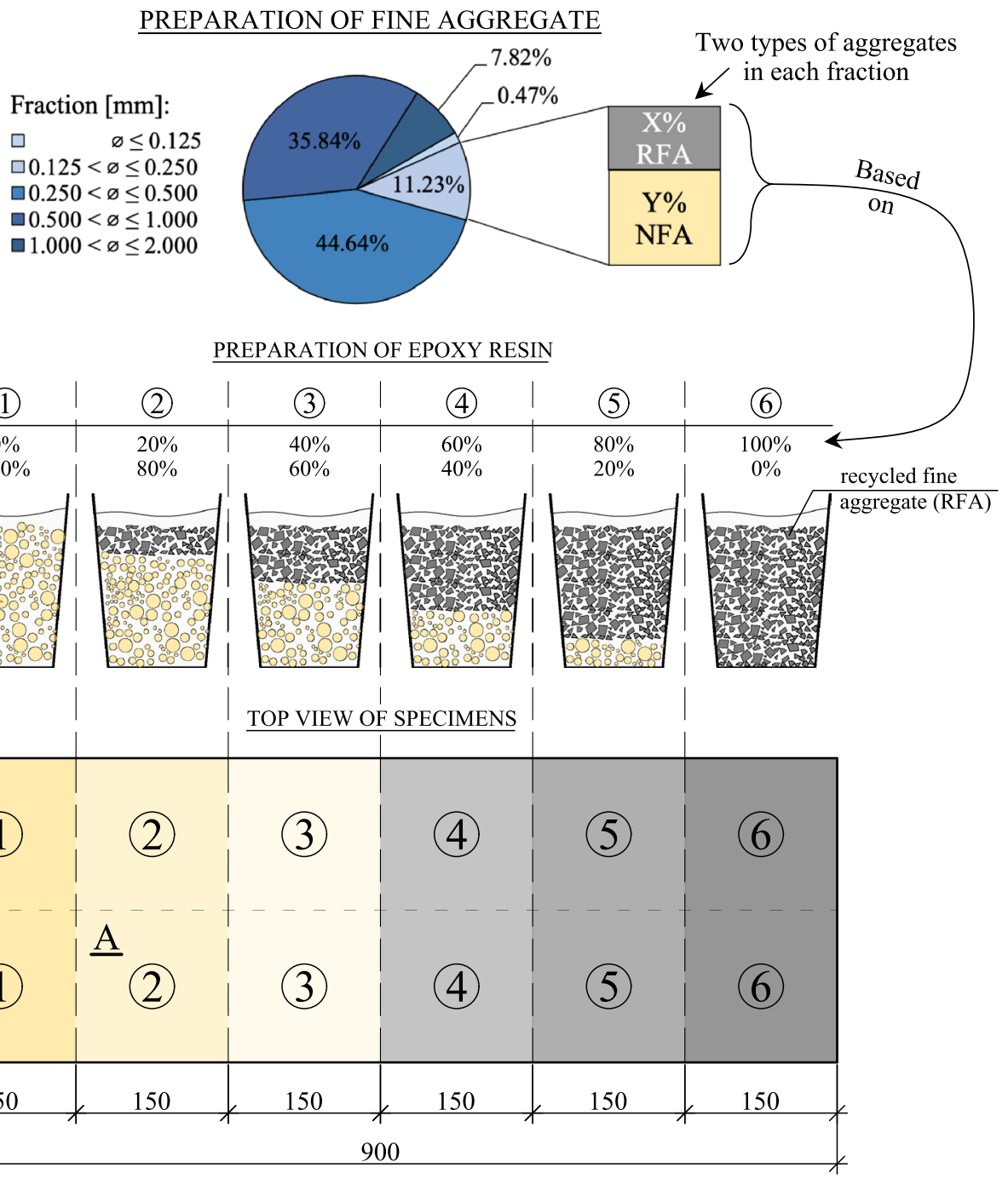

(d)

(b)

(c)
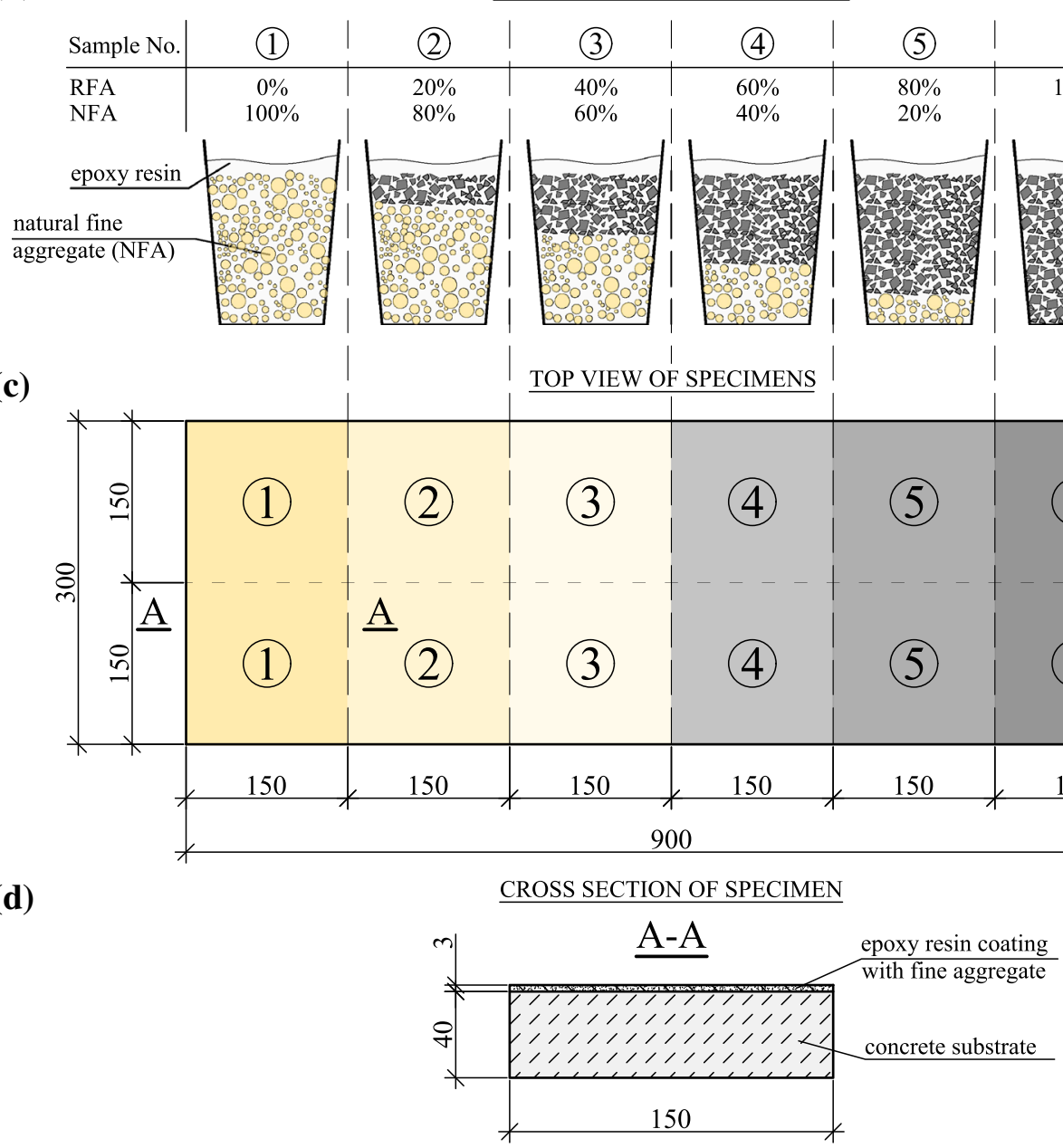

Fig. 4 Scheme of the preparation process of the samples: a mixing RFA and NFA fractions; $\mathbf{b}$ epoxy resin with different amounts of RFA and NFA; $\mathbf{c}$ top view of the specimens after the application of

using an X-ray micro-CT scanner with an 11 MP CCD camera (GE phoenix vltomelx s, General Electric Measurements, Boston, USA). All projections (1028) were reconstructed with Phoenix Datoslx CT software (General Electric Measurements, Boston, USA). Each sample was scanned using $140 \mathrm{kV}$ source energy and a $0.5 \mathrm{~mm} \mathrm{Cu}$ filter. Image processing was done in a similar way as in paper [71] by using CTAnalyser software version 1.17 (SkyScan, Kontich, Belgium). Prior to the evaluation of morphological parameters, epoxy resin on the concrete substrate-a darker color of the sample means a higher amount of RFA in the epoxy resin; $\mathbf{d}$ cross section of the prepared specimen

the grains connected to the edge of the analysed volume were rejected. Erosion and dilation operations were performed in order to separate the grains. As a result, the morphological factors were determined, i.e. the distribution of the sphericity, surface and size of grains.

The particle/element content analysis was performed using SEM and EDS for the NFA and the RFA, respectively. Five measurements for each type of aggregate were performed in order to ensure repeatability. The content of 
(a)

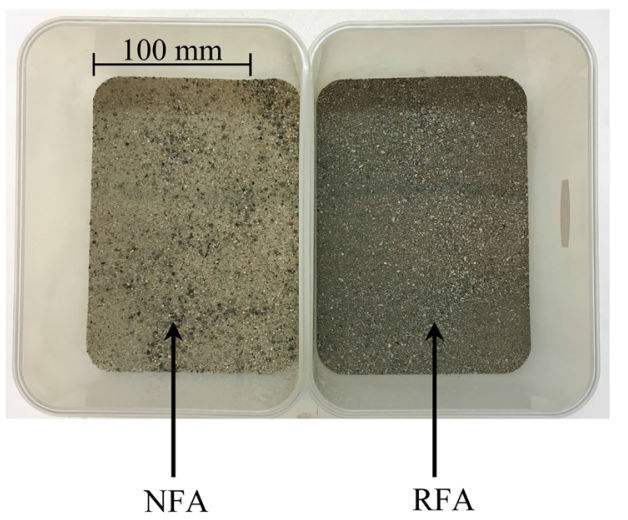

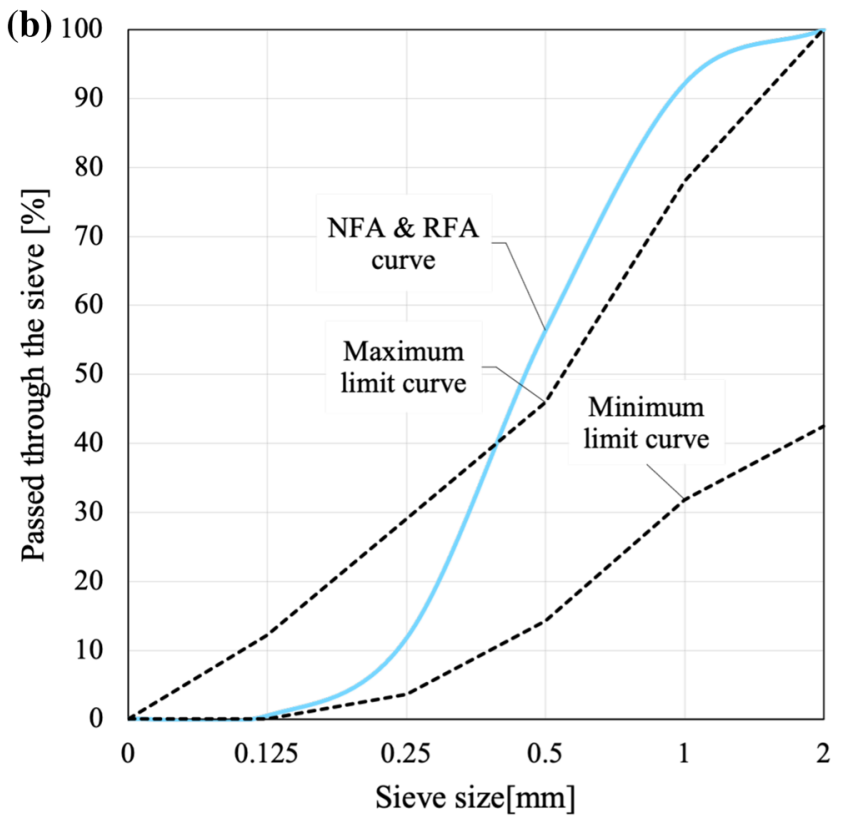

Fig. 5 The preparation process of the aggregates: a appearance of the two types of aggregate after the sieve process; $\mathbf{b}$ the aggregates' grain size distribution

Table 2 NFA properties

\begin{tabular}{ll}
\hline Property & Description \\
\hline $\mathrm{SiO}_{2}[\%]$ & 87.78 \\
Loose bulk den- & 1.50 \\
sity of material & \\
{$\left[\mathrm{g} / \mathrm{cm}^{3}\right]$} & \\
Aggregate bulk & 2.60 \\
density $\left[\mathrm{g} / \mathrm{cm}^{3}\right]$ & \\
\hline
\end{tabular}

elements/particles below $1 \%$ was not taken into account in the analysis.

In order to compare the mechanical parameters of the NFA and RFA, an MCT microindenter (Anton Paar) with a Berkovich probe was used. For each sample, the standard loading program was used, i.e. one loading-unloading cycle up to the maximum force of $50 \mathrm{mN}$ with a constant load rate of $100 \mathrm{mN} / \mathrm{min}$. The classical approach by Oliver and Pharr was applied to evaluate the indentation parameters ( $M$ and H) $[72,73]$.

Moreover, the epoxy resin was characterized by means of nanoindentation using a Berkovich indenter. A series of measurements with $15 \mu \mathrm{m}$ spacing, in the direction parallel to the interface and in the direction perpendicular to the interface, was provided. An $\mathrm{X}-\mathrm{Y}$ indentation grid with $34 \times 16$ measuring points, and an indentation force of 20 $\mathrm{mN}$, was applied. The loading and unloading rates were
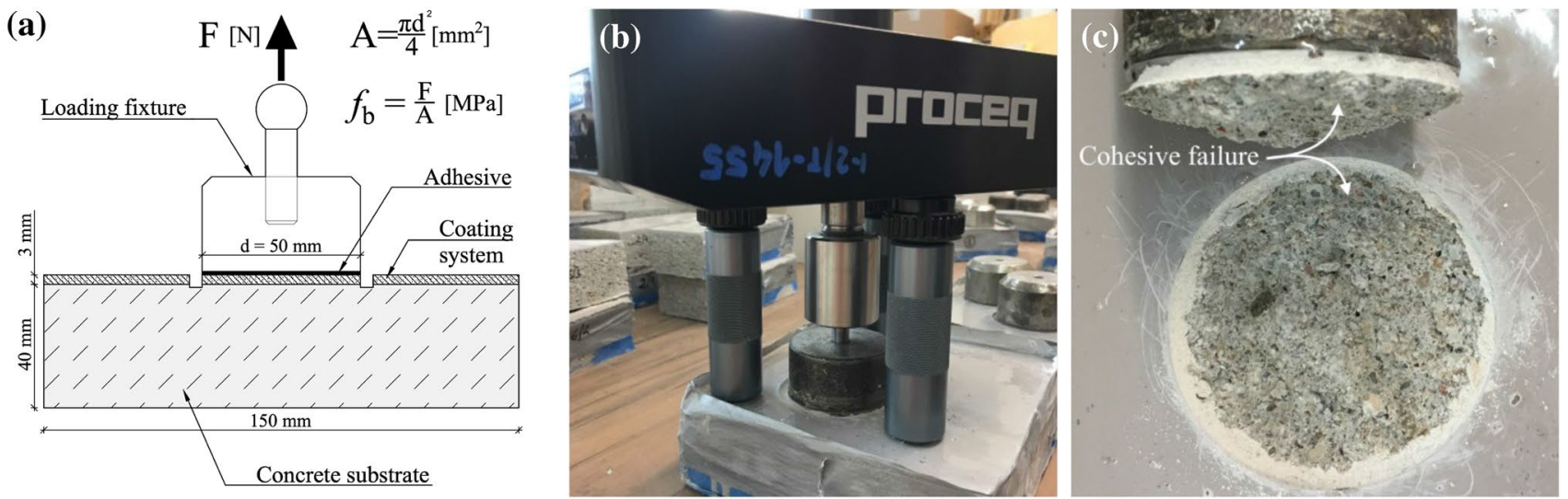

Fig. 6 The pull-off strength test $(\mathbf{a}, \mathbf{b})$ and cohesive failure (c) 
about $40 \mathrm{mN} / \mathrm{min}$. More information about the nanoindentation procedure is given in [74].

\section{Results and Discussion}

\subsection{Microscale Analysis}

\subsubsection{Micro-computed Tomography}

Three-dimensional (3D) reconstructed micro-CT images of the NFA, MFA, and RFA are presented in Fig. 7. The figure shows the segmented grains of each type of investigated aggregate. The volume fractions of the aggregate were $64.0 \%, 62.4 \%$, and $62.2 \%$ for the NFA, MFA, and RFA, respectively. The sphericity value, grain surface, and $D_{\max }$ to $D_{\min }$ ratio were established for each selected volume (Fig. 7). The exemplary histograms of the grain surface for all the aggregate types are shown in Fig. 8 . Gamma and Gaussian distributions were fitted to the experimental data. It can be seen that the most commonly used Gaussian distribution does not properly reflect the obtained data. Therefore, the Gamma distribution was used while describing the micro-CT results (see Fig. 9), as it much better correlates with the experimental data (Fig. 8). Based on the $k$ (shape factor) and $\theta$ (scale factor) parameters, the mean value and variance were determined for each measurement. These values are summarized in Table 3. Comparable sphericity was obtained for each aggregate type. In turn, a slightly lower (by 5\%) object surface can be noticed for the MFA when compared to the OFA and RFA. For all the aggregate types, the $D_{\max }$ to $D_{\min }$ ratio is within the range of $1-2.5$, with the mean value equal to $\sim 1.7$. This indicates that the grains have a high variability of shapes, which are far from perfect spheres. Although the micro-CT results are highly variable, they did not show any significant differences in the basic morphological characteristics for all the investigated types of aggregates.

\subsubsection{Scanning Electron microscopy}

Exemplary SEM images of the NFA and RFA are presented in Fig. 10a-b. The performed EDS analysis revealed the presence of $\mathrm{Si}, \mathrm{Ca}, \mathrm{Al}$, and $\mathrm{Fe}$ (in at. \%) (see Fig. 10c). No significant difference in the atomic percent was found with regards to the $\mathrm{Si}, \mathrm{Ca}$, and $\mathrm{Al}$. There was a residual content

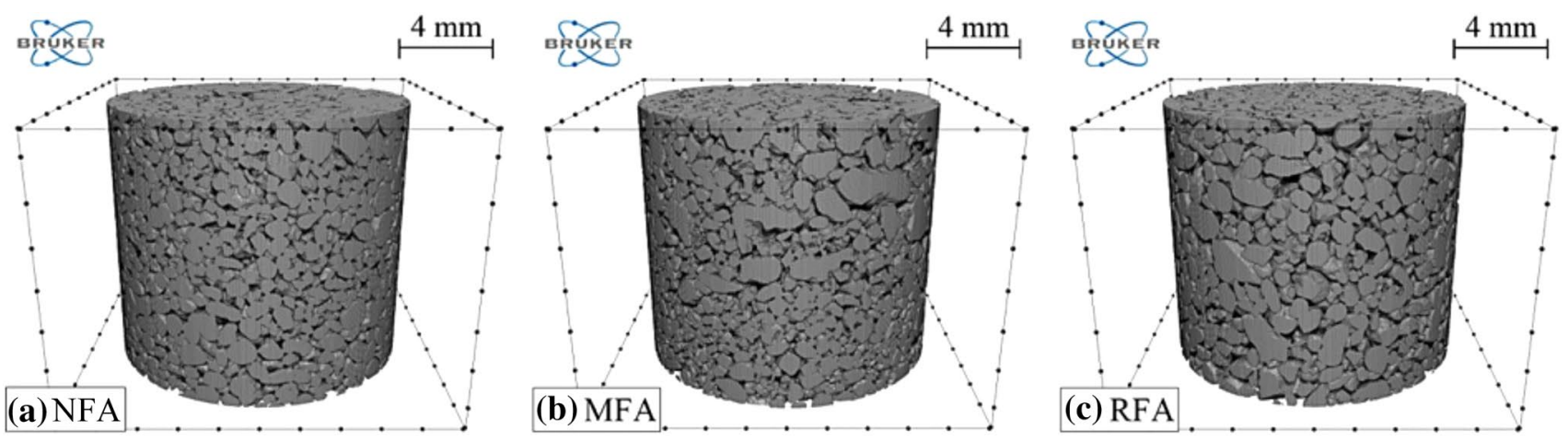

Fig. 7. 3D micro-computed tomography images for samples: a NFA, b MFA and $\mathbf{c}$ RFA
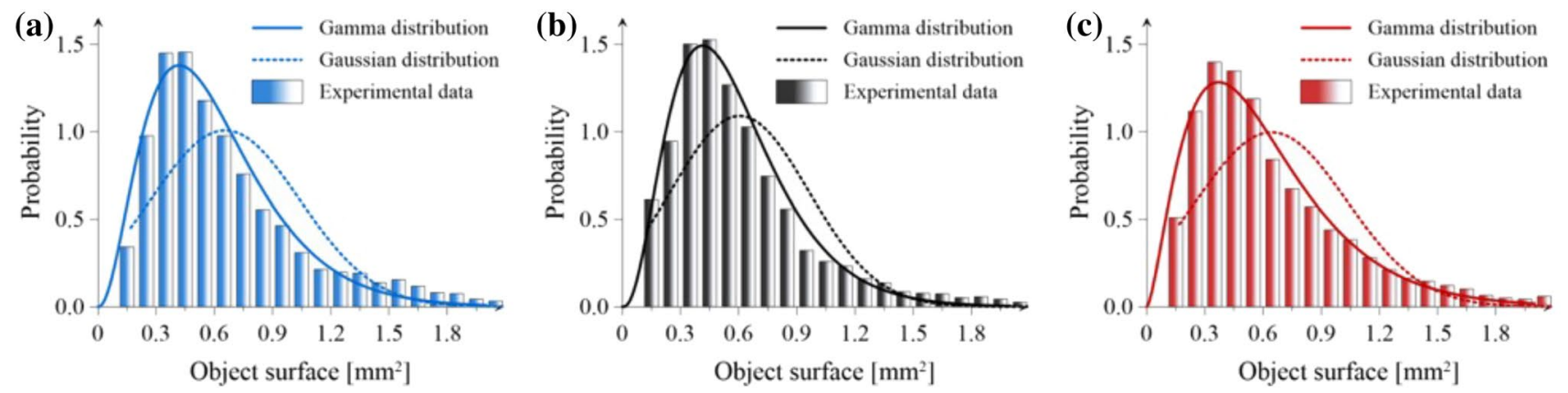

Fig. 8 Experimental grain surface distribution and its fitted Gamma and Gaussian distributions for samples: a NFA, b MFA and c RFA 

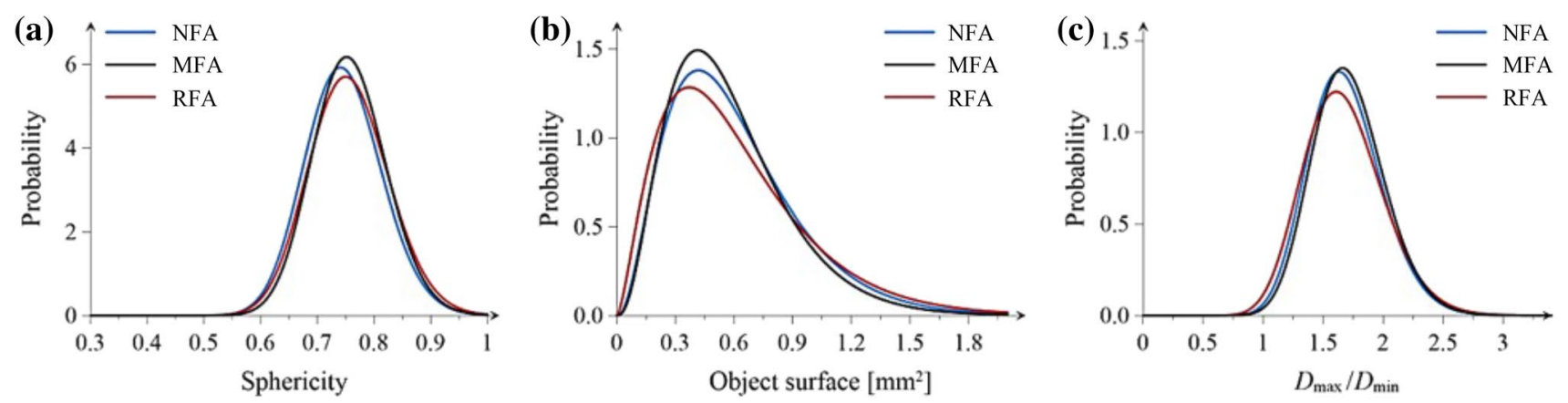

Fig. 9 Micro-computed tomography results of: a sphericity, b object surface and $\mathbf{c} D_{\max } / D_{\min }$ ratio of the aggregate-Gamma distributions fitted to the experimental results

Table 3 Gamma distribution parameters $(k$ and $\theta)$, as well as mean values and variance, for the sphericity, object surface, and $D_{\max }$ to $D_{\min }$ ratio

\begin{tabular}{llllll}
\hline Measurement & Aggregate & $k$ & $\theta$ & Mean value & Variance \\
\hline Sphericity & NFA & 122 & 0.00612 & 0.747 & 0.00457 \\
& MFA & 137 & 0.00554 & 0.757 & 0.00419 \\
& RFA & 116 & 0.00652 & 0.757 & 0.00494 \\
Object surface & NFA & 3.25 & 0.186 & 0.604 & 0.1124 \\
{$\left[\mathrm{~mm}^{2}\right]$} & MFA & 3.56 & 0.162 & 0.577 & 0.0935 \\
& RFA & 2.58 & 0.235 & 0.606 & 0.1424 \\
$D_{\max } / D_{\min }$ ratio & NFA & 30.8 & 0.0548 & 1.686 & 0.0924 \\
& MFA & 32.8 & 0.0522 & 1.713 & 0.0894 \\
& RFA & 25.4 & 0.0659 & 1.674 & 0.1103 \\
\hline
\end{tabular}

of Fe in the RFA (4.0\% when compared to $0 \%$ in the NFA). This may be due to the contact of the concrete with a corroded reinforcement.

\subsubsection{Nanoindentation}

For each aggregate type (NFA and RFA), 140-180 randomly located indentations were performed. As a result, histograms of their indentation modulus $(M)$ and indentation hardness $(H)$ were obtained (see Fig. 11). The indentation modulus for the NFA and RFA was equal to $70.8 \pm 12.9 \mathrm{GPa}$ and $56.0 \pm 15.8 \mathrm{GPa}$, respectively. The RFA was characterized by a lower mean value of $M$ (of about 20\%), and a higher standard deviation of $M$ (of about $25 \%$ ) in comparison to the NFA. The same trend occurred for the $H$ values; $H=8.3 \pm 2.3 \mathrm{GPa}$ for the NFA, and $H=6.9 \pm 2.9 \mathrm{GPa}$ for the RFA.

According to Fig. 12b-d, the hardness of the resin with embedded aggregate ranges from 0.4 to $22.7 \mathrm{GPa}$, with an average value of around $0.8 \mathrm{GPa}$. In turn, the indentation modulus changes from 1 to $97 \mathrm{GPa}$, with an average of 14 $\mathrm{GPa}$. The hardness of the epoxy resin itself was $0.4 \pm 0.1$ $\mathrm{GPa}$, and its elastic modulus was $6.1 \pm 1.3 \mathrm{GPa}$.
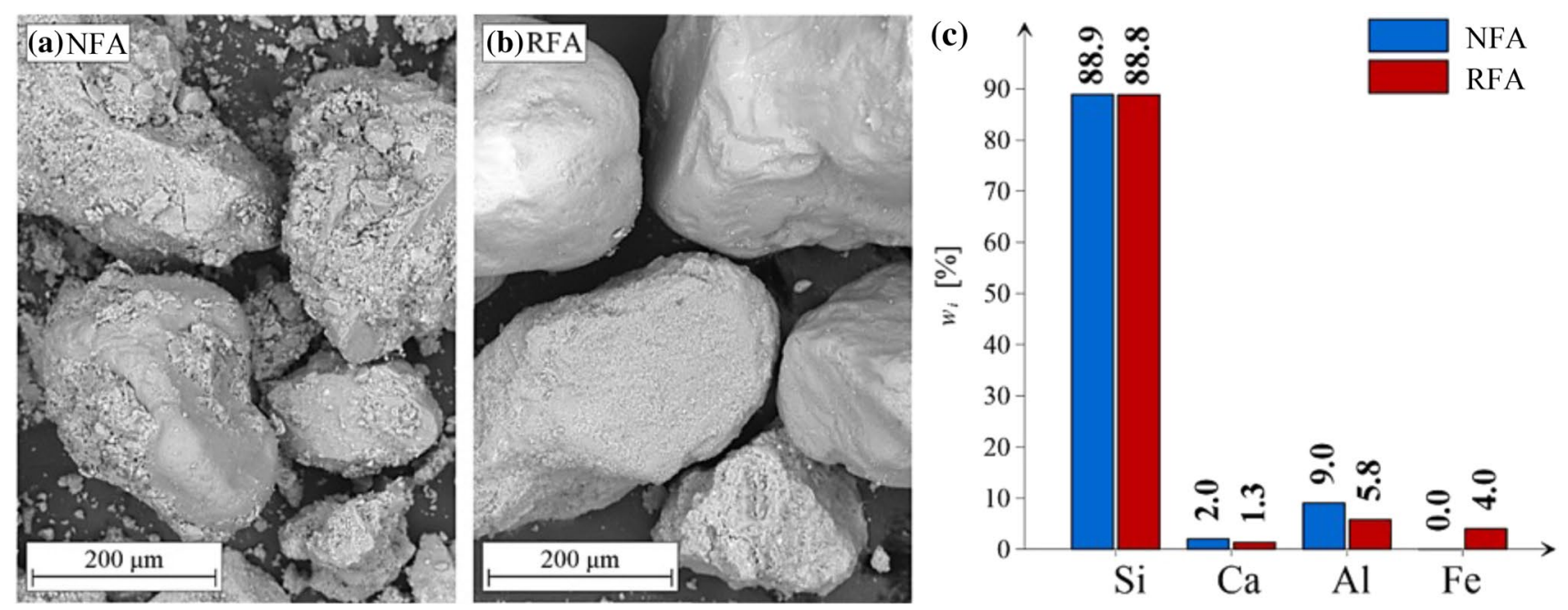

Fig. 10 Exemplary SEM images for the NFA (a) and RFA (b), as well as a graph of the atomic concentrations $\left(w_{i}\right)$ of $\mathrm{Si}, \mathrm{Ca}, \mathrm{Al}$ and $\mathrm{Fe}(\mathbf{c})$ 

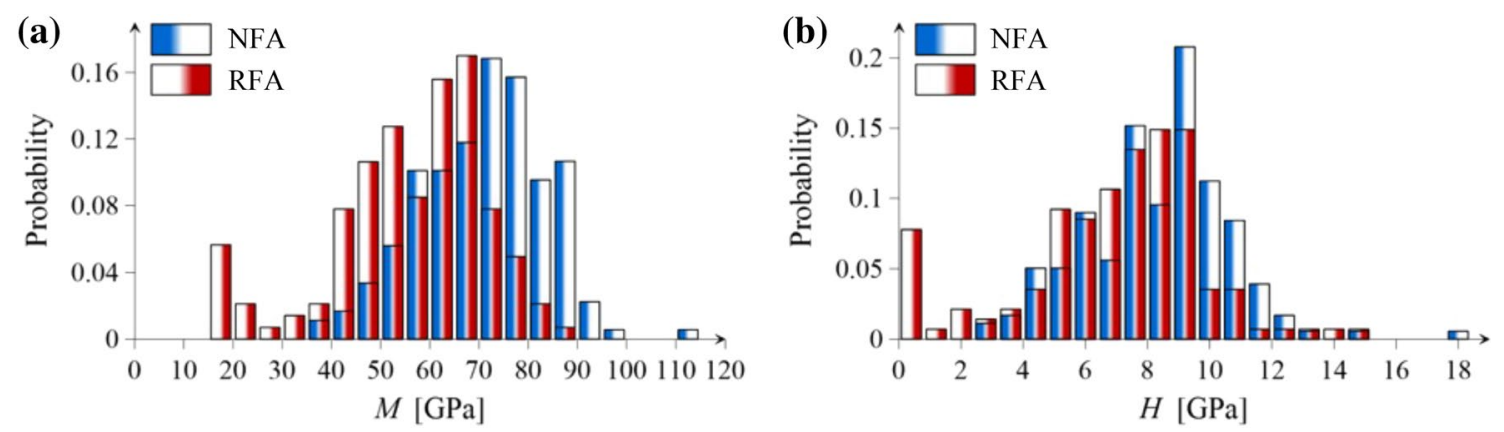

Fig. 11 Histograms of: a indentation modulus $(M)$ and $\mathbf{b}$ indentation hardness $(H)$ for the NFA and RFA
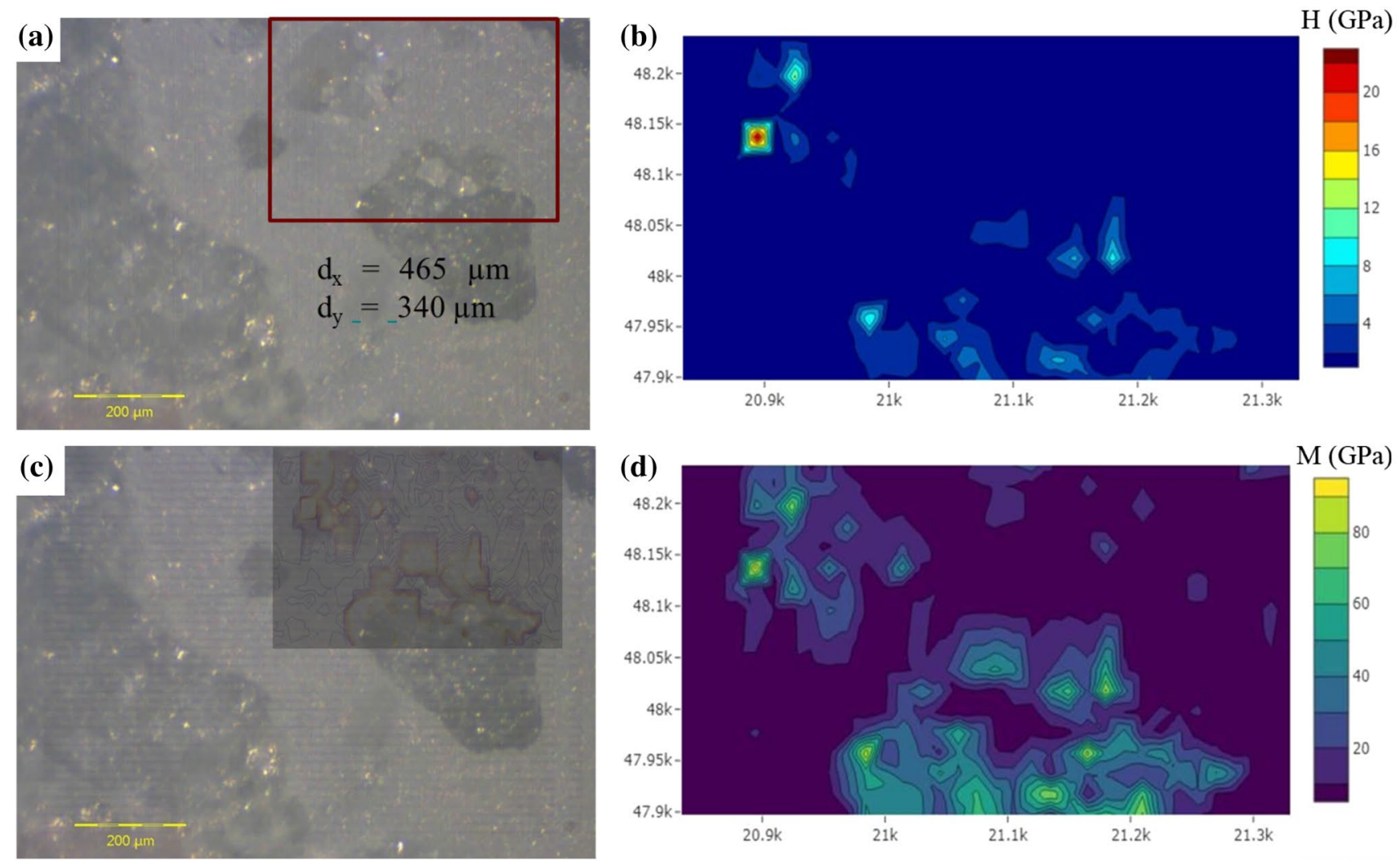

Fig. 12 a Optical micrograph of the epoxy-aggregate-composition with the indentation zone marked; $\mathbf{b}$ hardness (H) map; $\mathbf{c}$ indentation modulus distribution over the sample; $\mathbf{d}$ indentation modulus (M) map within the indentation zone

\subsection{Macroscale Analysis}

According to Fig. 13, the sample with $100 \%$ NFA $(0 \%$ RFA) added to the epoxy resin mixture (1.19 $\mathrm{MPa} \pm 0.29)$ has the lowest pull-off strength. A slightly better result of $f_{\mathrm{b}}=1.48 \mathrm{MPa}( \pm 0.30)$ was obtained for the sample with $40 \%$ of the RFA. Samples with 80 and $100 \%$ of RFA have similar pull-off strengths: $1.89 \mathrm{MPa}( \pm 0.09)$ and $1.93 \mathrm{MPa}$ $( \pm 0.09)$, respectively. The negative deviation of the strength for $40 \%$ of RFA is within the range of accuracy due to the dispersion of the selected places for the test. The destruction model for each sample was cohesive. Thus, the influence of the parameters of the subsurface zone of the concrete substrate, which is heterogeneous, may also significantly affect the results. However, each sample with the addition of RFA obtains better results in comparison to the reference sample with NFA. The cohesive failure mechanism shows that the adhesion between the epoxy resin coating and the concrete substrate surface is sufficient to transfer the pulloff stress. For the sample with the $100 \%$ RFA content, the 


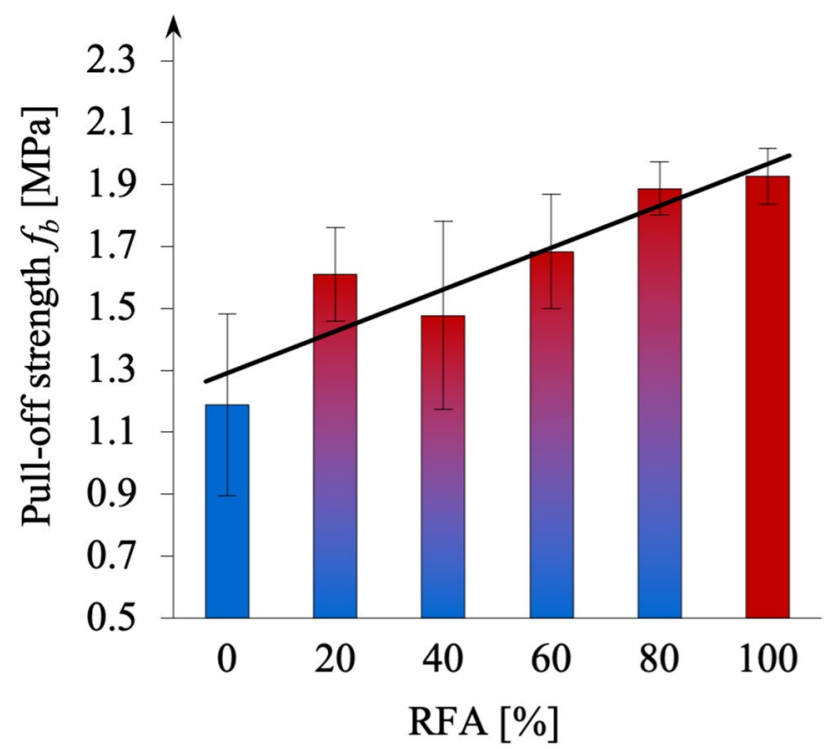

Fig. 13 Pull-off strength test results

highest pull-off strength (with the smallest standard deviation) was obtained in the case of three measurements. The thickness of the detached concrete substrate was between 2 and $7 \mathrm{~mm}$. In a previous study [52], the thickness of the detached concrete substrate was much greater in the case of textured surfaces, in turn significantly increasing the pull-off strength. Nevertheless, a higher RFA content (60-100\%) in the coating when not texturing the surface of the concrete substrate provides very good results.

\subsection{Compilation of the Obtained Results}

It can be seen in Fig. 14 that the type of extender (NFA or RFA) has an influence on the pull-off strength of the epoxy resin to the concrete substrate. The low value of the indentation modulus and the high mean object surface significantly improved the pull-off strength.

\subsection{Failure Mechanism}

Khedmati et al. [75] pointed out that mixtures that include crushed recycled aggregates have multiple complex aggregate/paste interphase regions when compared to conventional concrete mixtures, which in turn means that there are significant technical challenges in understanding and characterization of their properties. In this study, the authors wanted to explain the failure mechanisms during the pull-off strength tests, which occur in composite elements made of epoxy resin with RFA and concrete substrate.

Stress and strain are correlated using Young's modulus and Poisson's ratio (for isotropic material) [76]. Materials with a lower value of Young's modulus are more deformable.

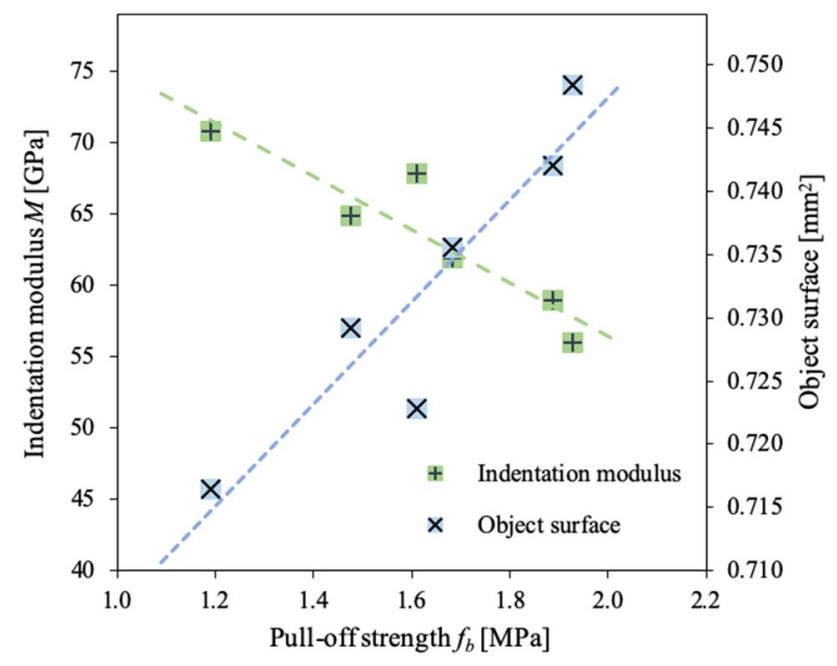

Fig. 14 Relationship between the obtained results

Lower values of the indentation modulus (which is related to Young's modulus) show that RFA is a more deformable and flexible material than NFA. The larger surface of the RFA grains when compared to the NFA grains probably results in a better interaction with the epoxy resin, which may be the reason for a more even stress distribution in the epoxy resin layer. All the failures that occurred during the pull-off strength tests were cohesive, which means that the crack origin is in the concrete substrate. The coating layer only transfers the stress.

Based on the analyses and obtained results, the authors designed a scheme to explain the behavior of the composite elements during the pull-off strength tests (Fig. 15). The stress transmission in epoxy resin coating is not uniform. This is mostly related to different Young's modulus values for each material in the composite. Therefore, stress $\sigma_{2}$, which is transmitted by the bonds between the epoxy resin and aggregate, is stronger than the stress $\sigma_{1}$ that is transmitted by the epoxy resin (during the pull-off strength test). When comparing the two materials (NFA and RFA) and their indentation modulus, it is evident that they have different deformability. In the case of the parallel static model, the stress $\sigma_{2}$ in the coating with the NFA will always be stronger than the stress $\sigma_{2}$ in the coating with the RFA. This is due to the fact that RFA has more similar properties to epoxy resin (than NFA), and that there is a better interaction during loading.

When summarizing the above, due to the fact that there is less uniform stress transmission in the epoxy resin coating with the NFA, the stress $\sigma_{2, \mathrm{NFA}}$ that causes the cracking of the concrete layer is stronger than the stress $\sigma_{1, \mathrm{NFA}}$. The stress $\sigma_{2, \mathrm{NFA}}$ in also greater than the stress $\sigma_{2, \mathrm{RFA}}$ in the coating with the RFA (when analyzing models loaded with the same force $F$ ). It means that there is a faster crack 

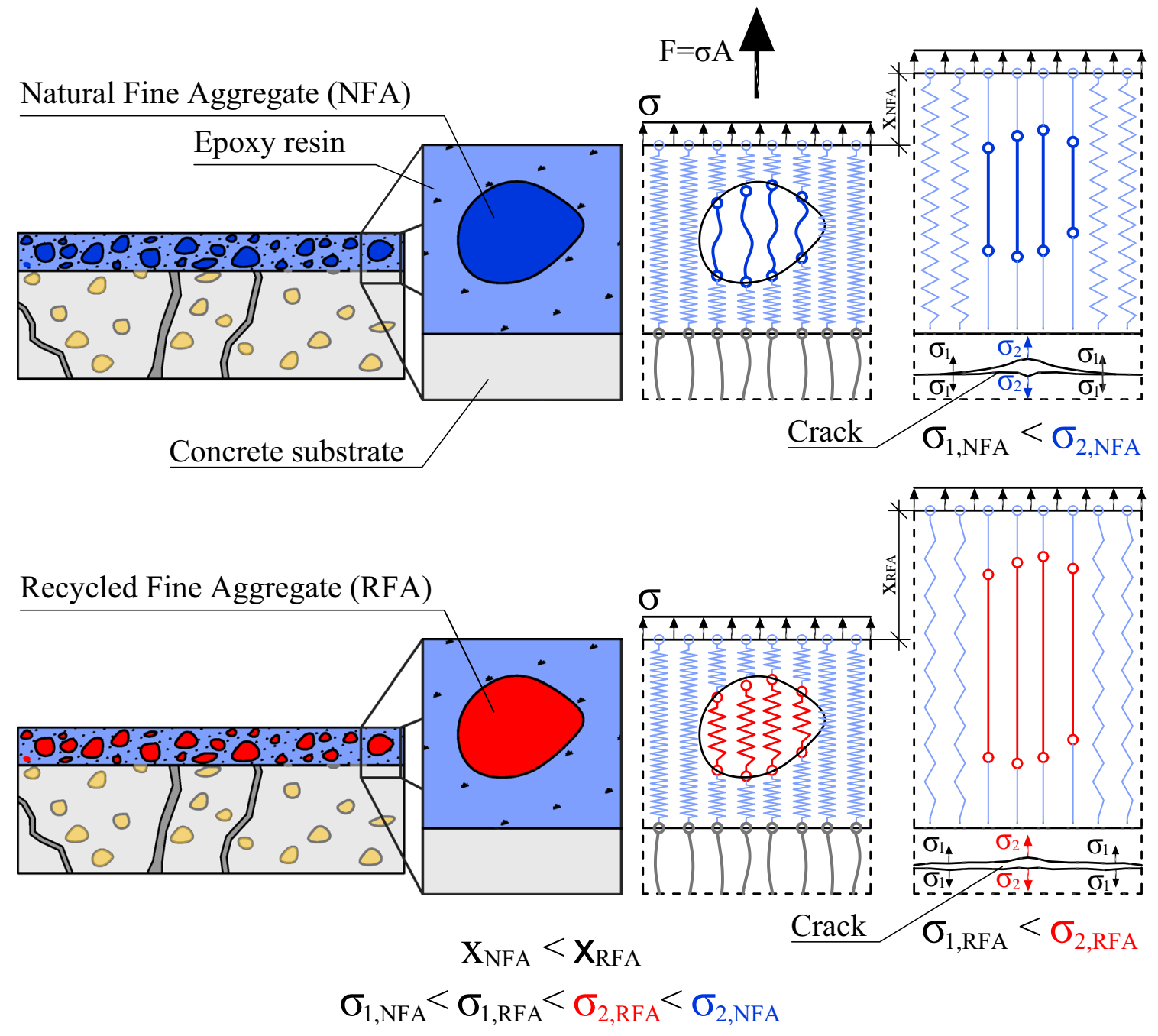

Fig. 15 Scheme of the failure mechanism of the composite during the pull-off strength test

propagation in the sample with NFA when compared to the sample with RFA. As a result, the samples with the bigger amount of NFA obtained the maximum value of concrete subsurface tensile strength when loaded with a lower pulloff load $F$.

\subsubsection{Analytical Approach}

Based on the previously presented mechanism, the authors carried out analytical calculations, which enabled the share of the aggregate in the destruction mechanism to be confirmed.

To calculate the crack load $F_{2}$ in concrete, Eq. (1) is used to develop a static model (presented in Fig. 16). The static model was prepared based on three assumptions:

- because of the volume ratio of the aggregate to the epoxy resin of 0.6, the epoxy resin always covers the aggregate,
- due to the limited height of the coating $(3 \mathrm{~mm})$ and the greater volume of the epoxy resin than the aggregate, the flexible springs that define the behavior of the epoxy resin surround the less flexible springs of the aggregate,

- the simplified static model distinguishes different Young moduli $E$, areas $A$ and lengths $L$ for each material (based on Sects. 2 and 3.1.3).

$$
k=\frac{E A}{L}=\frac{F}{\delta}
$$

Based on the adopted static model, it was possible to calculate the stiffness for each elastic spring (2), (3), (4) and (5).

$$
k_{1, N F A}=\frac{1}{\frac{1}{k_{e 1}}+\frac{1}{k_{c 1}}},
$$




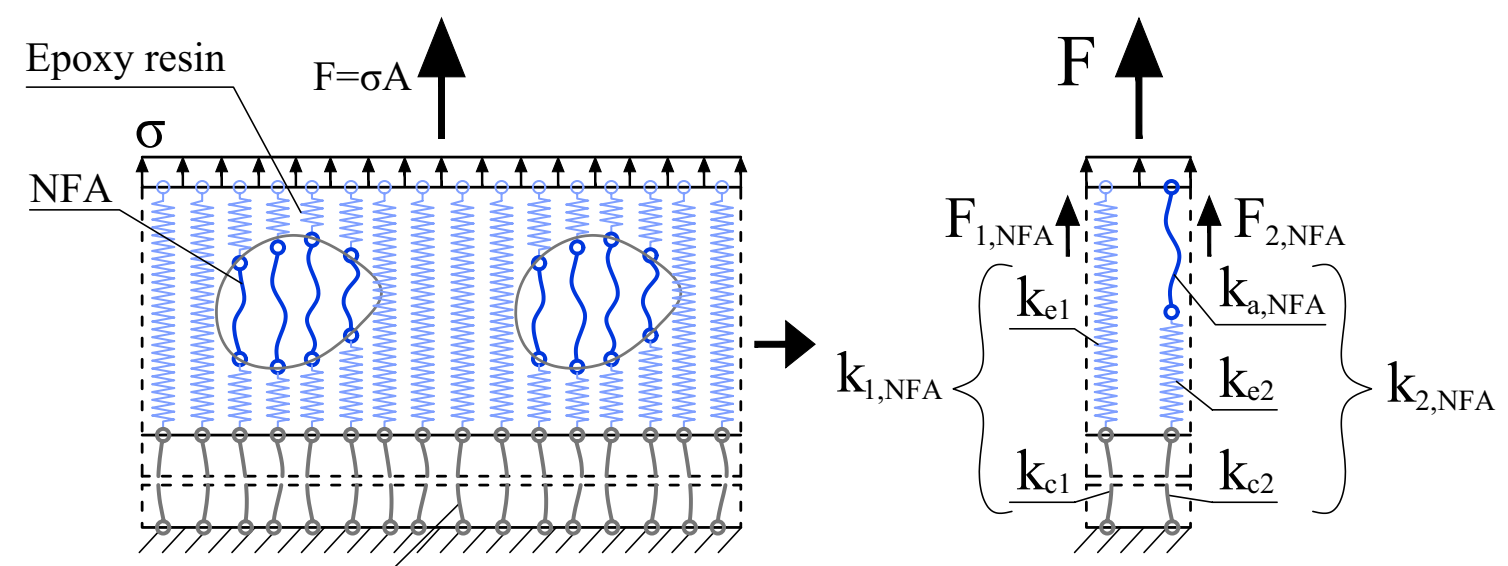

Concrete substrate

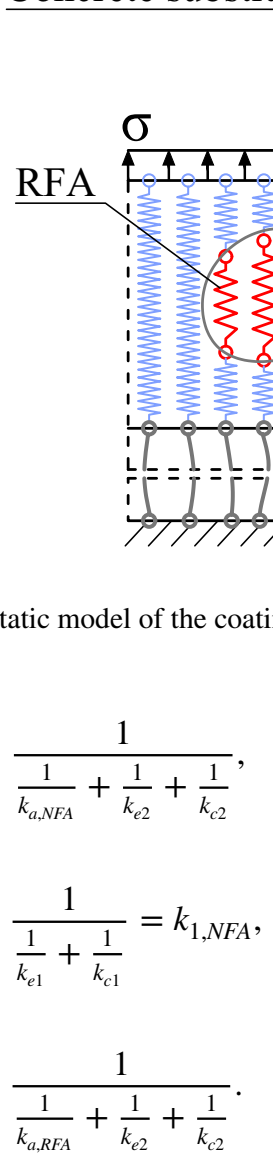

When the elastic springs are parallel, their force is different (depending on their stiffness $k(6)$ ).

$F=F_{1}+F_{2}=k_{1} \cdot x+k_{2} \cdot x$.

According to the model, for the same pull-off force for two different coatings (7), it is possible to show (using (8)) that $k_{2, \mathrm{NFA}}$ is greater than $k_{2, \mathrm{RFA}}$ and that $x_{\mathrm{NFA}}$ is lower than $x_{\mathrm{RFA}}(10)$. Due to the different deformations for each of the coatings, and the same values of $k_{1, \mathrm{NFA}}$ and $k_{1, \mathrm{RFA}}$, force $F_{1}$ in the epoxy resin with the RFA is higher than that in the epoxy resin with the NFA (11). In contrast, the force $F_{2}$ is higher for the epoxy resin with the NFA when compared to the epoxy resin with the RFA (12)

$F_{N F A}=F_{R F A}$,

$k_{1, N F A} \cdot x_{N F A}+k_{2, N F A} \cdot x_{N F A}=k_{1, R F A} \cdot x_{R F A}+k_{2, R F A} \cdot x_{R F A}$,

$\left(k_{1, N F A}+k_{2, N F A}\right) \cdot x_{N F A}=\left(k_{1, R F A}+k_{2, R F A}\right) \cdot x_{R F A}$,

$k_{1, R F A}=k_{1, N F A} \rightarrow k_{2, N F A}>k_{2, R F A} \rightarrow x_{N F A}<x_{R F A}$,

$F_{1, N F A}=k_{1, N F A} \bullet x_{N F A}<F_{1, R F A}=k_{1, R F A} \bullet x_{R F A}$,

$F_{2, N F A}=k_{2, N F A} \cdot x_{N F A}>F_{2, R F A}=k_{2, R F A} \cdot x_{R F A}$,

When substituting the actual values for parameters $E, A$, and $L$ for the coatings with the NFA and RFA, force $F_{2}$ was larger than force $F_{1}(13),(14)$ :

$F_{1, N F A}<F_{2, N F A}$, 
$F_{1, R F A}<F_{2, R F A}$.

Based on the results from (11), (12), (13), and (14), the forces are organized in (15) from the lowest value to the highest:

$F_{1, N F A}<F_{1, R F A}<F_{2, R F A}<F_{2, N F A}$.

The bigger the differences between the forces (16) in the analyzed static model, the less uniform the stress transferred in the concrete is. The calculations show that larger differences occur for coatings with NFA than for coatings with RFA (17). Therefore, cracks can occur faster in the concrete substrate layer when the sample is loaded with a smaller force $F$ during the pull-off test.

$\delta=F_{2}-F_{1}$,

$\delta_{N F A}>\delta_{R F A}$.

\subsubsection{Numerical Approach}

To confirm the assumed failure mechanism, as well as the behavior of the coatings with different extenders, a numerical model was prepared based on the values obtained in the study. ZSoil software was used to set up the numerical model (Fig. 17).

According to the model, the shear stress $\sigma_{\mathrm{xy}}$ is higher in the coating with NFA than in the coating with RFA (Fig. 18). The maximum shear stress in the concrete substrate is $-20.98 \mathrm{MPa}$ for the NFA, and $-20.61 \mathrm{MPa}$ for the RFA.
Therefore, the cracking, which always occurs in the concrete layer, is obtained with a lower pull-off force in the coatings with the NFA. This is due to a less uniform stress transmission when compared to the coatings with the RFA The failure propagates faster in mortar when a coating made of epoxy resin with NFA is used.

For the pure epoxy resin, the shear stress within the substrate was almost zero (Fig. 18a). If an aggregate has properties close to those of epoxy resin, the transmission of stress is more uniform. This can help to obtain better pull-off strength results and improve the durability of the coating.

\section{Conclusion}

Environmental protection plays a key role for humanity. Processes with a damaging impact on the environment should be regulated or changed in order to reduce their negative effects. In this work, the negative effects of demolishing buildings were reduced by substituting natural fine aggregate with recycled fine aggregate from industrial wastes. When summarizing the test results, each sample with the RFA obtained better pull-off strength results, whereas the sample with the $100 \%$ RFA content obtained the best result (1.93 MPa \pm 0.15). The replacement of NFA with RFA has a positive impact on the pull-off strength of epoxy resin. Micro-computed tomography results indicated that the preparation process of RFA was very efficient. Sphericity and object surface histograms of the NFA and RFA were very similar. The mean value of sphericity for the NFA was 0.747 , and for the RFA was 0.757 (with a 0.010 difference). The mean value of the object surface for the NFA was 0.604 $\mathrm{mm}^{2}$, and for the RFA it was $0.002 \mathrm{~mm}^{2}$ higher. The mean
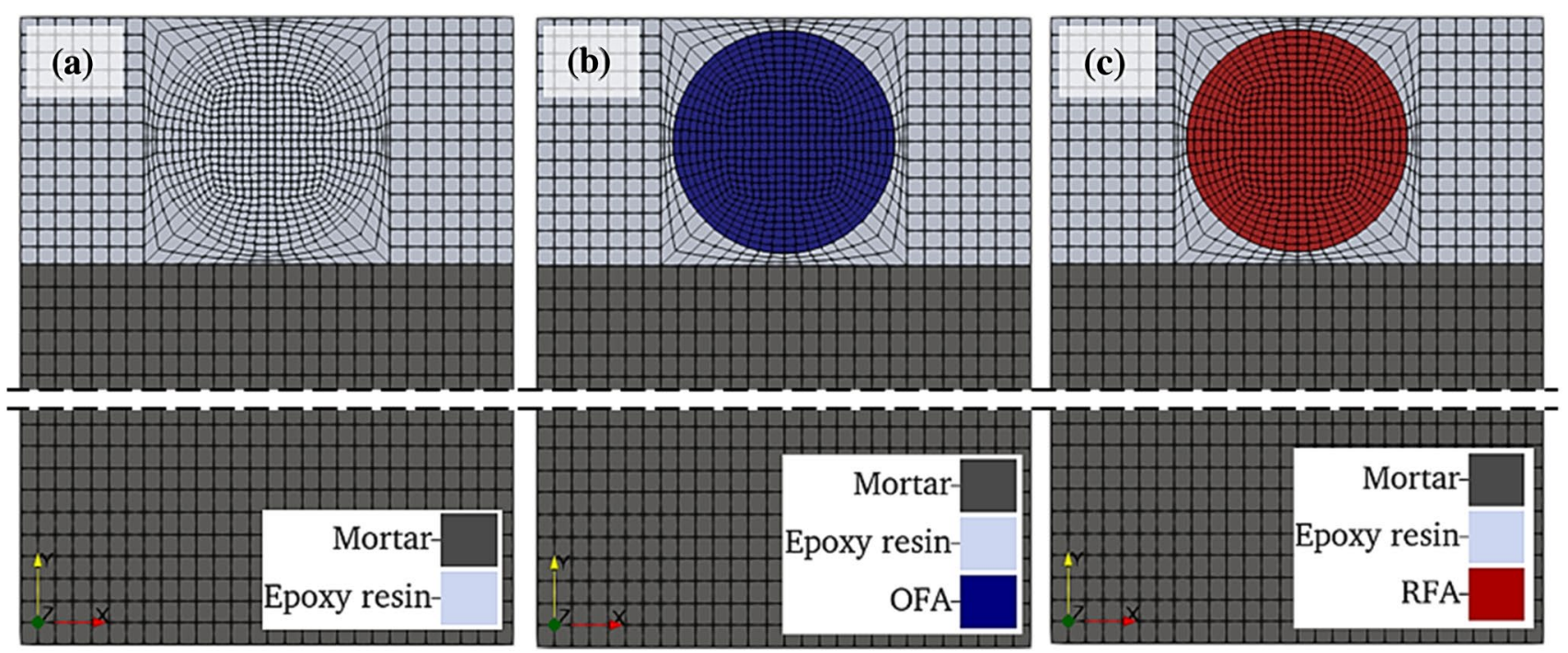

Fig. 17 Numerical model for the epoxy resin (a), epoxy resin with the NFA (b), and epoxy resin with the RFA (c) 

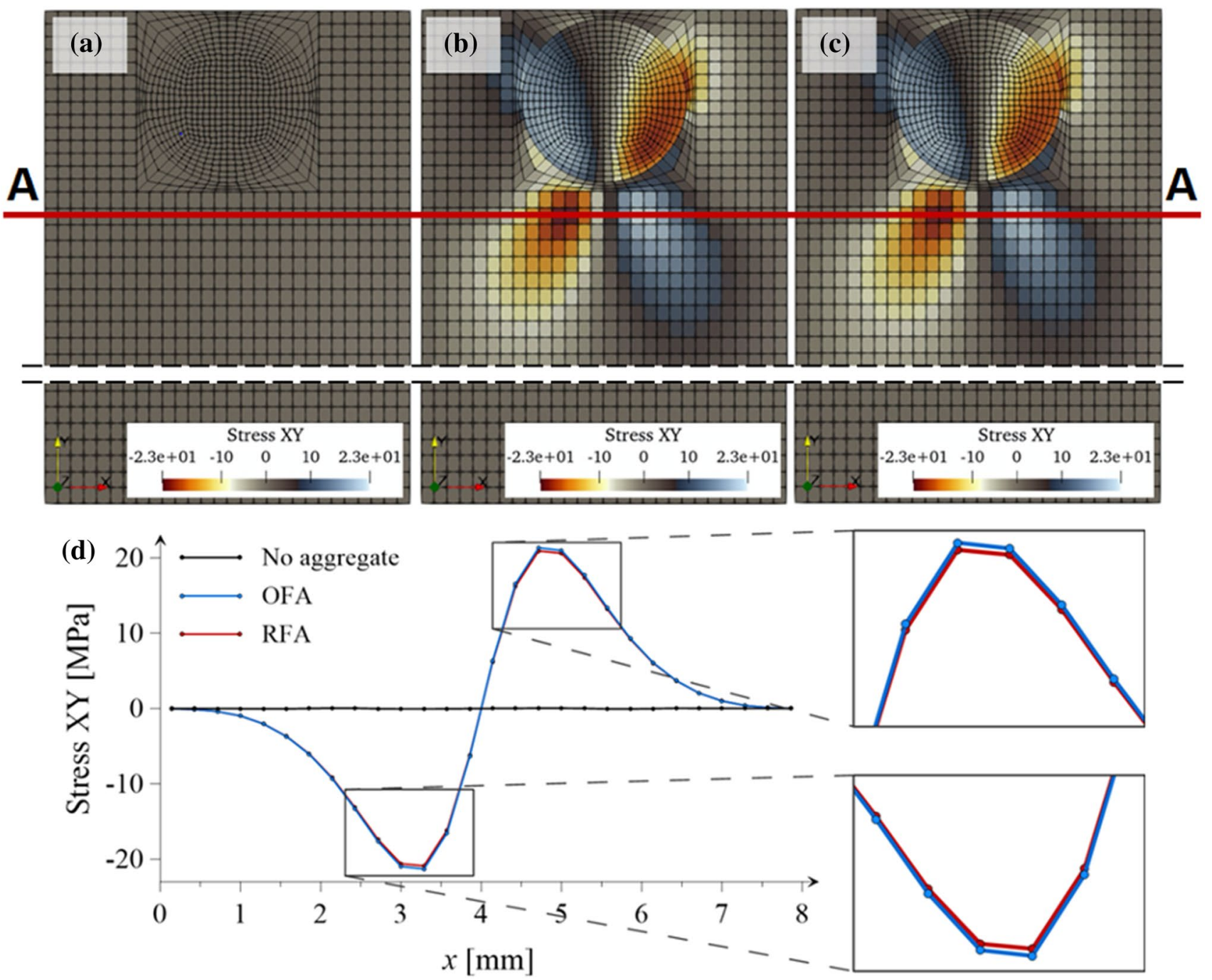

Fig. 18 Results of the shear stress $\sigma_{x y}$ for the epoxy resin (a), the epoxy resin with the NFA (b), the epoxy resin with the RFA (c), and also the shear stress $\sigma_{\mathrm{xy}}$ in cross-section $\mathrm{A}-\mathrm{A}(\mathbf{d})$ of each numerical model (with vertical stress of $5 \mathrm{MPa}$ applied to the top surface)

value of the $D_{\max }$ to $D_{\min }$ ratio for the NFA and RFA was 1.686 and 1.674 , respectively. The variance for all the measured properties was similar for both aggregates. It shows that the preparation process of the aggregates was accurate enough to obtain a very similar aggregate grain size distribution for each sample with different amounts of RFA and NFA. The hardness of the RFA, NFA and epoxy resin was 6.9, 8.3 and $0.8 \mathrm{GPa}$, respectively. Nanoindentation revealed lower values (by about 20\%) of indentation modulus, as well as hardness, for the RFA (56.0 GPa) samples when compared to the NFA (70.8 GPa) samples. Therefore, the wear resistance of the epoxy resin coatings as a function of the RFA-content will be part of our subsequent research. The lower indentation modulus of the RFA when compared to the NFA may be the reason for the more even transfer of stresses to the concrete substrate. Higher pull-off strength results for the samples with the RFA were obtained. The assumed failure mechanism was confirmed by analytical calculations and the numerical model of stress distribution during the pull-off strength test. A potential decrease of the cost of coatings, combined with a high pull-off strength and a Young modulus that is close to that of epoxy resin, will qualify RFA as a good extender that can be used in epoxy resin coatings. The presented studies show that samples with RFA do not have a worse pull-off strength than samples that contain mainly NFA. Moreover, an increasing RFA content in a coating allows a better pull-off strength to be obtained. From an environmental point of view, it is profitable to use RFA in epoxy resin coating compositions.

Acknowledgements The authors are thankful to Dr. Holger Großmann (Anton Paar Germany $\mathrm{GmbH}$ ) for his help in nanoindentation measurements and technical support. Damian Stefaniuk is grateful for the financial support of the Foundation for Polish Science (FNP) (START 2020). The work was initiated thanks to the internship completed 
by Łukasz Sadowski at Brandenburg Technical University, Department of Physical Metallurgy and Materials Technology in the period from 11.07.2019 to 13.10.2019 within the SARCOS COST Action (CA15202).

Funding The authors received funding from a project supported by the National Centre of Science, Poland [Grant no. 2019/35/O/ST8/01546 "Multi-scale evaluation of the effect of thermal shock on the properties of environmentally-friendly polymer-cement composites modified with recycled fine aggregates (POWER)'’].

\section{Declarations}

Conflicts of interest The authors declare that there is no conflict of interest.

Open Access This article is licensed under a Creative Commons Attribution 4.0 International License, which permits use, sharing, adaptation, distribution and reproduction in any medium or format, as long as you give appropriate credit to the original author(s) and the source, provide a link to the Creative Commons licence, and indicate if changes were made. The images or other third party material in this article are included in the article's Creative Commons licence, unless indicated otherwise in a credit line to the material. If material is not included in the article's Creative Commons licence and your intended use is not permitted by statutory regulation or exceeds the permitted use, you will need to obtain permission directly from the copyright holder. To view a copy of this licence, visit http://creativecommons.org/licenses/by/4.0/.

\section{References}

1. Rödger, J. M., Beier, J., Schönemann, M., Schulze, C., Thiede, S., Bey, N., Herrmann, C., \& Hauschild, M. Z. (2021). Combining life cycle assessment and manufacturing system simulation: evaluating dynamic impacts from renewable energy supply on product-specific environmental footprints. International Journal of Precision Engineering and Manufacturing Green Technology. https://doi.org/10.1007/s40684-020-00229-z

2. Govindan, K., Madan Shankar, K., \& Kannan, D. (2016). Sustainable material selection for construction industry-a hybrid multi criteria decision making approach. Renewable and Sustainable Energy Reviews, 55, 1274-1288. https://doi.org/10.1016/j.rser. 2015.07.100

3. Martinico-Perez, M. F. G., Fishman, T., Okuoka, K., \& Tanikawa, H. (2017). Material flow accounts and driving factors of economic growth in the philippines. Journal of Industrial Ecology, 21, 1226-1236. https://doi.org/10.1111/jiec.12496

4. de Brito J, Saikia N (2013) Recycled Aggregate in Concrete: Use of Industrial, Construction and Demolition Waste. Springer, London

5. (2019) Eurostat Statistics - Waste Generation. https://ec.europa. eu/eurostat/statistics-explained/index.php/Waste_statistics

6. Material flow accounts. http://appsso.eurostat.ec.europa.eu/nui/ show.do?dataset=env_ac_mfa\&lang=en. Accessed 25 Jul 2019

7. Alev, Ü., Eskola, L., Arumägi, E., Jokisalo, J., Donarelli, A., Siren, K., Broström, T., \& Kalamees, T. (2014). Renovation alternatives to improve energy performance of historic rural houses in the Baltic Sea region. Energy and Buildings, 77, 58-66. https:// doi.org/10.1016/j.enbuild.2014.03.049

8. Kovacic, I., Summer, M., \& Achammer, C. (2015). Strategies of building stock renovation for ageing society. Journal of Cleaner
Production, 88, 349-357. https://doi.org/10.1016/j.jclepro.2014. 04.080

9. Vejmelková, E., Keppert, M., Keršner, Z., Rovnaníková, P., \& Cerný, R. (2012). Mechanical, fracture-mechanical, hydric, thermal, and durability properties of lime-metakaolin plasters for renovation of historical buildings. Construction and Building Materials, 31, 22-28. https://doi.org/10.1016/j.conbuildmat. 2011.12.084

10. Alexandridou, C., Angelopoulos, G. N., \& Coutelieris, F. A. (2018). Mechanical and durability performance of concrete produced with recycled aggregates from Greek construction and demolition waste plants. Journal of Cleaner Production, 176, 745-757. https://doi.org/10.1016/j.jclepro.2017.12.081

11. Shahidan S, Azmi MAM, Kupusamy K, Zuki SSM, Ali N (2017) Utilizing Construction and Demolition (C\&D) Waste as Recycled Aggregates (RA) in Concrete. In: Procedia Engineering. pp $1028-1035$

12. Marie, I., \& Quiasrawi, H. (2012). Closed-loop recycling of recycled concrete aggregates. Journal of Cleaner Production, 37, 243-248. https://doi.org/10.1016/j.jclepro.2012.07.020

13. Mefteh, H., Kebaïli, O., Oucief, H., Berredjem, L., \& Arabi, N. (2013). Influence of moisture conditioning of recycled aggregates on the properties of fresh and hardened concrete. Journal of Cleaner Production, 54, 282-288. https://doi.org/10.1016/j. jclepro.2013.05.009

14. Etxeberria, M., Vázquez, E., Marí, A., \& Barra, M. (2007). Influence of amount of recycled coarse aggregates and production process on properties of recycled aggregate concrete. Cement and Concrete Research, 37, 735-742. https://doi.org/10.1016/j.cemco nres.2007.02.002

15. Sagoe-Crentsil, K. K., Brown, T., \& Taylor, A. H. (2001). Performance of concrete made with commercially produced coarse recycled concrete aggregate. Cement and Concrete Research, 31, 707-712. https://doi.org/10.1016/S0008-8846(00)00476-2

16. Silva, R. V., de Brito, J., \& Dhir, R. (2019). Use of recycled aggregates arising from construction and demolition waste in new construction applications. Journal of Cleaner Production. https://doi. org/10.1016/j.jclepro.2019.117629

17. Bassani, M., Tefa, L., Coppola, B., \& Palmero, P. (2019). Alkaliactivation of aggregate fines from construction and demolition waste: Valorisation in view of road pavement subbase applications. Journal of Cleaner Production, 234, 71-84. https://doi.org/ 10.1016/j.jclepro.2019.06.207

18. Poon, C. S., \& Chan, D. (2006). Feasible use of recycled concrete aggregates and crushed clay brick as unbound road sub-base. Construction and Building Materials, 20, 578-585. https://doi.org/10. 1016/j.conbuildmat.2005.01.045

19. André, A., De Brito, J., Rosa, A., \& Pedro, D. (2014). Durability performance of concrete incorporating coarse aggregates from marble industry waste. Journal of Cleaner Production, 65, 389396. https://doi.org/10.1016/j.jclepro.2013.09.037

20. Arel, H. S. (2016). Recyclability of waste marble in concrete production. Journal of Cleaner Production, 131, 179-188.

21. Uygunoł̣lu, T., Topçu, I. B., \& Çelik, A. G. (2014). Use of waste marble and recycled aggregates in self-compacting concrete for environmental sustainability. Journal of Cleaner Production, 84, 691-700. https://doi.org/10.1016/j.jclepro.2014.06.019

22. Binici, H., Shah, T., Aksogan, O., \& Kaplan, H. (2008). Durability of concrete made with granite and marble as recycle aggregates. Journal of Materials Processing Technology, 208, 299-308. https://doi.org/10.1016/j.jmatprotec.2007.12.120

23. Ismail, S., \& Ramli, M. (2014). Mechanical strength and drying shrinkage properties of concrete containing treated coarse recycled concrete aggregates. Construction and Building Materials, 68, 726-739. https://doi.org/10.1016/j.conbuildmat.2014.06.058 
24. Sharma, N. K., Kumar, P., Kumar, S., Thomas, B. S., \& Gupta, R. C. (2017). Properties of concrete containing polished granite waste as partial substitution of coarse aggregate. Construction and Building Materials, 151, 158-163. https://doi.org/10.1016/j. conbuildmat.2017.06.081

25. Keshavarz, Z., \& Mostofinejad, D. (2019). Steel chip and porcelain ceramic wastes used as replacements for coarse aggregates in concrete. Journal of Cleaner Production, 230, 339-351. https:// doi.org/10.1016/j.jclepro.2019.05.010

26. Medina, C., Sánchez De Rojas, M. I., \& Frías, M. (2013). Freezethaw durability of recycled concrete containing ceramic aggregate. Journal of Cleaner Production, 40, 151-160. https://doi. org/10.1016/j.jclepro.2012.08.042

27. Evangelista, B. L., Rosado, L. P., \& Penteado, C. S. G. (2018). Life cycle assessment of concrete paving blocks using electric arc furnace slag as natural coarse aggregate substitute. Journal of Cleaner Production, 178, 176-185. https://doi.org/10.1016/j. jclepro.2018.01.007

28. Palankar, N., Ravi Shankar, A. U., \& Mithun, B. M. (2016). Durability studies on eco-friendly concrete mixes incorporating steel slag as coarse aggregates. Journal of Cleaner Production, 129, 437-448. https://doi.org/10.1016/j.jclepro.2016.04.033

29. Qasrawi, H. (2018). Fresh properties of green SCC made with recycled steel slag coarse aggregate under normal and hot weather. Journal of Cleaner Production, 204, 980-991. https://doi.org/10. 1016/j.jclepro.2018.09.075

30. Gao, C., Huang, L., Yan, L., Jin, R., \& Kasal, B. (2019). Strength and ductility improvement of recycled aggregate concrete by polyester FRP-PVC tube confinement. Engineering Composites Part B. https://doi.org/10.1016/j.compositesb.2018.10.102

31. Evangelista, L., \& de Brito, J. (2007). Mechanical behaviour of concrete made with fine recycled concrete aggregates. Cement and Concrete Composites, 29, 397-401. https://doi.org/10.1016/j. cemconcomp.2006.12.004

32. Evangelista, L., \& de Brito, J. (2010). Durability performance of concrete made with fine recycled concrete aggregates. Cement and Concrete Composites, 32, 9-14. https://doi.org/10.1016/j.cemco ncomp.2009.09.005

33. Khatib, J. M. (2005). Properties of concrete incorporating fine recycled aggregate. Cement and Concrete Research, 35, 763-769. https://doi.org/10.1016/j.cemconres.2004.06.017

34. Rodrigues, F., Carvalho, M. T., Evangelista, L., \& De Brito, J. (2013). Physical-chemical and mineralogical characterization of fine aggregates from construction and demolition waste recycling plants. Journal of Cleaner Production, 52, 438-445. https://doi. org/10.1016/j.jclepro.2013.02.023

35. Saiz Martínez, P., González Cortina, M., Fernández Martínez, F., \& Rodríguez Sánchez, A. (2016). Comparative study of three types of fine recycled aggregates from construction and demolition waste $(\mathrm{CDW})$, and their use in masonry mortar fabrication. Journal of Cleaner Production, 118, 162-169. https://doi.org/10. 1016/j.jclepro.2016.01.059

36. Jin, X., Zhang, X., \& Luo, Y. (2010). A calculation method for the floor surface temperature in radiant floor system. Energy and Buildings, 42, 1753-1758. https://doi.org/10.1016/j.enbuild.2010. 05.011

37. Sadowski, K. K., \& Michoń, M. (2020). The influence of texturing of the surface of concrete substrate on its adhesion to cement mortar overlay. Journal of Adhesion, 96, 130-143. https://doi.org/ 10.1080/00218464.2019.1654383

38. Tabsh, S. W., \& Abdelfatah, A. S. (2009). Influence of recycled concrete aggregates on strength properties of concrete. Construction and Building Materials, 23, 1163-1167. https://doi.org/10. 1016/j.conbuildmat.2008.06.007
39. Mikami, T., Kang, Y. H., \& Choi, S. K. (2015). Judging indices for evaluating the exfoliation of synthetic resin floorings using the impact acoustics method. Construction and Building Materials, 95, 345-354. https://doi.org/10.1016/j.conbuildmat.2015.07.133

40. Sadowski, C. S., \& Hoła, J. (2016). Evaluation of the height 3D roughness parameters of concrete substrate and the adhesion to epoxy resin. International Journal of Adhesion and Adhesives. https://doi.org/10.1016/j.ijadhadh.2015.12.019

41. Wei H, Xia J, Zhou W, Zhou L, Hussain G, Li Q, Ostrikov K (Ken) (2020) Adhesion and cohesion of epoxy-based industrial composite coatings. Composites Part B: Engineering

42. Jin, F. L., Li, X., \& Park, S. J. (2015). Synthesis and application of epoxy resins: a review. Journal of Industrial and Engineering Chemistry, 29, 1-11.

43. Kim, M. T., Rhee, K. Y., Park, S., \& Hui, D. (2012). Effects of silane-modified carbon nanotubes on flexural and fracture behaviors of carbon nanotube-modified epoxy/basalt composites. Composites Part B: Engineering, 43, 2298-2302. https://doi.org/10. 1016/j.compositesb.2011.12.007

44. Song, G. S. (2005). Buttock responses to contact with finishing materials over the ONDOL floor heating system in Korea. Energy and Buildings, 37, 65-75. https://doi.org/10.1016/j.enbuild.2004. 05.005

45. Wu, G., Kong, Z., Chen, J., Huo, S., \& Liu, G. (2014). Preparation and properties of waterborne polyurethane/epoxy resin composite coating from anionic terpene-based polyol dispersion. Progress in Organic Coatings, 77, 315-321. https://doi.org/10.1016/j.porgc oat.2013.10.005

46. Jeon, H. R., Park, J. H., \& Shon, M. Y. (2013). Corrosion protection by epoxy coating containing multi-walled carbon nanotubes. Journal of Industrial and Engineering Chemistry, 19, 849-853. https://doi.org/10.1016/j.jiec.2012.10.030

47. Vakili, H., Ramezanzadeh, B., \& Amini, R. (2015). The corrosion performance and adhesion properties of the epoxy coating applied on the steel substrates treated by cerium-based conversion coatings. Corrosion Science, 94, 466-475. https://doi.org/10.1016/j. corsci.2015.02.028

48. Zhai, L., Ling, G., Li, J., \& Wang, Y. (2006). The effect of nanoparticles on the adhesion of epoxy adhesive. Materials Letters, 60, 3031-3033. https://doi.org/10.1016/j.matlet.2006.02.038

49. Sadowski Ł (2019) Adhesion in Layered Cement Composites, 1st ed. Cham

50. Szymanowski J, Sadowski Ł (2017) Ultrasonic pulse velocity evaluation of the pull-off adhesion between epoxy resin and concrete substrate. In: Key Engineering Materials. pp 390-395

51. Colangelo, F., Russo, P., Cimino, F., Cioffi, R., Farina, I., Fraternali, F., \& Feo, L. (2017). Epoxy/glass fibres composites for civil applications: comparison between thermal and microwave crosslinking routes. Engineering Composites Part B. https://doi. org/10.1016/j.compositesb.2017.06.003

52. Krzywiński, K., \& Sadowski, Ł. (2019). The effect of texturing of the surface of concrete substrate on the pull-off strength of epoxy resin coating. Coatings, 9, 143. https://doi.org/10.3390/coatings 90 20143

53. Huan, X., Shi, K., Yan, J., Lin, S., Li, Y., Jia, X., \& Yang, X. (2020). High performance epoxy composites prepared using recycled short carbon fiber with enhanced dispersibility and interfacial bonding through polydopamine surface-modification. Engineering Composites Part B. https://doi.org/10.1016/j.compositesb.2020. 107987

54. Song JH, Min SH, Kim SG, Cho Y, Ahn SH (2021) Multi-functionalization Strategies Using Nanomaterials: A Review and Case Study in Sensing Applications. International Journal of Precision Engineering and Manufacturing Green Technology 
55. Chowaniec, A., \& Ostrowski, K. (2018). Epoxy resin coatings modified with waste glass powder for sustainable construction. Czasopismo Techniczne, 8, 99-109. https://doi.org/10.4467/23537 37XCT.18.118.8893

56. Lian, W., Liu, Y., Wang, W., Dong, Y., Wang, S., Liu, Z., \& Liu, Y. (2021). Preparation of environmentally friendly low-cost mullite porous Ceramics and the effect of Waste Glass Powder on structure and mechanical Properties. International Journal of Precision Engineering and Manufacturing-Green Technology. https:// doi.org/10.1007/s40684-021-00333-8

57. Krzywiński, K., Sadowski, Ł, \& Piechówka-Mielnik, M. (2021). Engineering of composite materials made of epoxy resins modified with recycled fine aggregate. Science and Engineering of Composite Materials, 28, 276-284. https://doi.org/10.1515/ secm-2021-0029

58. Ahmad, A., Farooq, F., Ostrowski, K. A., Śliwa-Wieczorek, K., \& Czarnecki, S. (2021). Application of novel machine learning techniques for predicting the surface chloride concentration in concrete containing waste material. Materials. https://doi.org/10. 3390/ma14092297

59. Chajec, A. (2021). Granite powder vs. Fly ash for the sustainable production of air-cured cementitious mortars. Materials. https:// doi.org/10.3390/ma14051208

60. Krzywiński K, Sadowski $Ł$ (2022) The Effect of Recycled Fine Aggregate Sourced from Construction and Demolition Waste on the Properties of Epoxy Resin Coatings. In: Cunha VMCF (ed) Proceedings of the 3rd RILEM Spring Convention and Conference (RSCC 2020), RILEM Bookseries 35. Springer Nature Switzerland AG

61. Safier AS (1989) Development and use of electrostatic, epoxypowder coated reinforcement. Structural engineer London

62. Al-Turaif, H. A. (2010). Effect of nano TiO2 particle size on mechanical properties of cured epoxy resin. Progress in Organic Coatings, 69, 241-246. https://doi.org/10.1016/j.porgcoat.2010. 05.011

63. Frigione, M., Aiello, M. A., \& Naddeo, C. (2006). Water effects on the bond strength of concrete/concrete adhesive joints. Construction and Building Materials, 20, 957-970. https://doi.org/10. 1016/j.conbuildmat.2005.06.015

64. Leone, M., Matthys, S., \& Aiello, M. A. (2009). Effect of elevated service temperature on bond between FRP EBR systems and concrete. Composites Part B: Engineering, 40, 85-93. https://doi.org/ 10.1016/j.compositesb.2008.06.004

65. British Standards Institution (2006) Products and Systems for the Protection and Repair of Concrete Structures-Test MethodsMeasurement of Bond Strength by Pull-Off. In: BS-EN 1542. London

66. Ren, Z., Fang, F., Yan, N., \& Wu, Y. (2021). State of the art in defect detection based on machine vision. International Journal of Precision Engineering and Manufacturing-Green Technology. https://doi.org/10.1007/s40684-021-00343-6

67. Ravimal, D., Kim, H., Koh, D., Hong, J. H., \& Lee, S. K. (2020). Image-based inspection technique of a machined metal surface for an unmanned lapping process. International Journal of Precision Engineering and Manufacturing - Green Technology. https://doi. org/10.1007/s40684-019-00181-7

68. Sto - Website. https://www.sto.pl. Accessed 19 Mar 2021

69. ASTM Committee D01.46. (2009). ASTM D4541-09 standard test method for pull-off strength of coatings using portable adhesion testers. Annual Book of ASTM Standards, 0602, 1-16. https:// doi.org/10.1520/D4541-09E01

70. Krzywiński, K., \& Sadowski, ŁM. (2020). The effect of the type of substrate and its surface treatment on the pull-off strength of gypsum plasters. Journal of Adhesion, 96, 370-383. https://doi. org/10.1080/00218464.2019.1653762
71. Michałek, J., Pachnicz, M., \& Sobótka, M. (2019). Application of nanoindentation and 2D and 3D imagingto characterise selected features of the internal microstructure of spun concrete. Materials. https://doi.org/10.3390/ma12071016

72. Oliver, W., \& Pharr, G. M. (1992). An improved technique for determining hardness and elastic modulus using load and displacement sensing indentation experiments. Journal of Materials Research, 7, 1564-1583. https://doi.org/10.1557/JMR.1992.1564

73. Oliver, W. C., \& Pharr, G. M. (2004). Measurement of hardness and elastic modulus by instrumented indentation: advances in understanding and refinements to methodology. Journal of Materials Research, 19, 3-20. https://doi.org/10.1557/jmr.2004.19.1.3

74. Sadowski, Ł, Stefaniuk, D., Żak, A., \& Krakowiak, K. J. (2019). Micromechanical properties within the interphase between heterogeneous layers made of cementitious composites. Construction and Building Materials, 215, 1033-1043. https://doi.org/10. 1016/j.conbuildmat.2019.04.238

75. Khedmati, M., Kim, Y. R., \& Turner, J. A. (2019). Investigation of the interphase between recycled aggregates and cementitious binding materials using integrated microstructural-nanomechanical-chemical characterization. Composites Part B: Engineering. https://doi.org/10.1016/j.compositesb.2018.09.041

76. Candappa, D. C., Sanjayan, J. G., \& Setunge, S. (2001). Complete triaxial stress-strain curves of high-strength concrete. Journal of Materials in Civil Engineering. https://doi.org/10. 1061/(ASCE)0899-1561(2001)13:3(209)

Publisher's Note Springer Nature remains neutral with regard to jurisdictional claims in published maps and institutional affiliations.

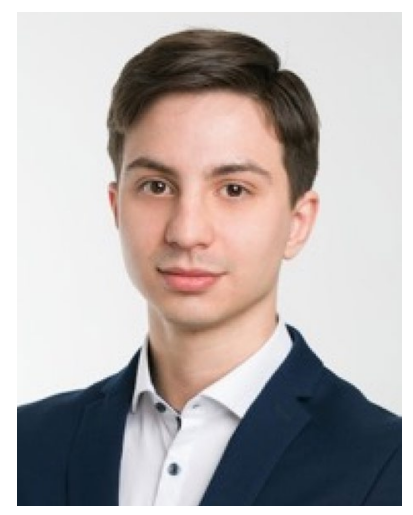

Kamil Krzywiński received his Master Degree (Hons) in Civill Engineering, Wroclaw University of Science and Technology (WUST), Poland in 2020. Also, in 2020 he was a laureate of the Polish Minister of Science and Higher Education scholarship for his achievements in science. Since 2020, he has been a PhD student at WUST. His current research interests include studies focused on modifications of epoxy resins and their possible application in civil engineering and construction industry.

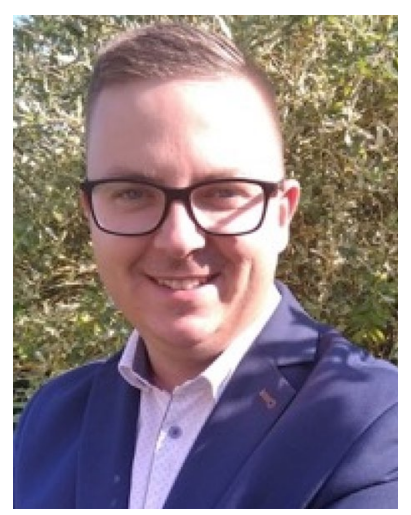

Łukasz Sadowski an Associate Professor at the Faculty of Civil Engineering, Wroclaw University of Science Technology (WUST), Poland. Łukasz obtained a MSc (Hons) in Civil Engineering from WUST in 2007, a PhD (Hons) in Civil Engineering from WUST in 2013 and a DSc (Hons) in Civil Engineering from WUST in 2018. He is the fellow of Foundation for Polish Science (FNP) and Ministry of Science and Higher Education (MNiSW). His research interests include con- 
crete, sustainable development, non-destructive testing, surface morphology, acoustic techniques and artificial intelligence.

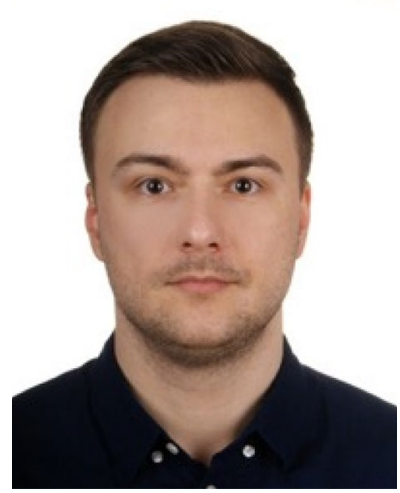

Damian Stefaniuk is an Assistant Professor at the Faculty of Civil Engineering, Wroclaw University of Science Technology (WUST), Poland and a Postdoc at the Department of Civil and Environmental Engineering, University of Houston, USA. He obtained a MSc (Hons) in Civil Engineering from WUST in 2013 and a PhD (Hons) in Civil Engineering from WUST in 2018. His research mainly focuses on, among others, inverse problems in micromechanics, cementitious composites investigation by means of nanoindentation and X-ray microtomography as well as numerical analysis of geotechnical problems.

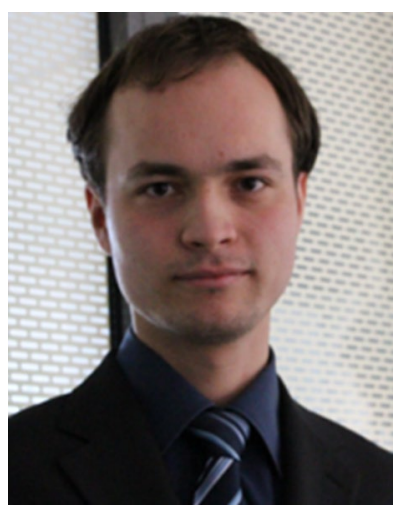

Aleksei Obrosov received his Master Degree in Metallurgy Technology form the Peter the Great St.Petersburg Polytechnic University (SPbPU), Russia in 2014 and Master Degree in Mechanical Engineering from Branderbur University of Technology (BUT), Germany in 2014. Since 2014, he has been employee at BUT. Since 2017, he is working as a Research Grup Leader at BUT. His studies are focuced on development and production of PVD layers (DCMS, Pulse MS, HPPMS).

His research interests include $\mathrm{x}$-ray diffraction and nanoindentation analysis.

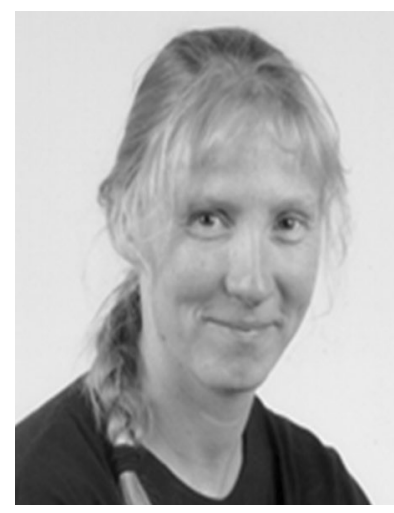

Sabine Weiß received her Diploma and Dr. Eng. Degree in Physical Metallurgy and Materials Science from the Technical University (RWTH) of Aachen, Germany in 1990 and 1997, respectively. As head of the fatigue group in the institute of product engineering, chair for materials science of the University Duisburg-Essen, Germany she completed her Habilitation in Materials Science and Engineering in 2007. Her research focused on the fields of texture analysis, grain growth, fatigue and microstructure analysis. Since 2012 she is Professor for Physical Metallurgy and Materials Technology at the Brandenburg Technical University of Cottbus. Her current research interest lies within the fields of materials characterization, erosion wear, development of protective coatings and mechanical properties of metals and intermetallic phases. 